\title{
Numerical Evaluations of Functionally Graded RC Slabs
}

\author{
M. Mastali, ${ }^{1}$ M. Mastali, ${ }^{2}$ Z. Abdollahnejad, ${ }^{3}$ M. Ghasemi Naghibdehi, ${ }^{4}$ \\ and M. K. Sharbatdar ${ }^{4}$ \\ ${ }^{1}$ ISISE, Department of Civil Engineering, University of Minho, 4800-058 Guimarães, Portugal \\ ${ }^{2}$ Faculty of Civil Engineering, Western Michigan University, Kalamazoo, MI 49008-5316, USA \\ ${ }^{3}$ C-TAC Research Centre, Department of Civil Engineering, University of Minho, 4800-058 Guimarães, Portugal \\ ${ }^{4}$ Faculty of Civil Engineering, Semnan University, Semnan 35131-19111, Iran
}

Correspondence should be addressed to M. Mastali; muhammad.mastali@gmail.com

Received 13 February 2014; Revised 12 July 2014; Accepted 13 July 2014; Published 10 September 2014

Academic Editor: Baozhong Sun

Copyright (C) 2014 M. Mastali et al. This is an open access article distributed under the Creative Commons Attribution License, which permits unrestricted use, distribution, and reproduction in any medium, provided the original work is properly cited.

Nowadays, using fibrous materials is used widely in strengthening applications such as cross-section enlargement and using functionally graded reinforced concrete. Functionally graded reinforced concrete is used as multireinforced concrete layers that can be reinforced by different fiber types. The objective of this research was to address the structural benefits of functionally graded concrete materials by performing analytical simulations. In order to achieve this purpose, in the first stage of this study, three functionally graded reinforced concretes by steel and polypropylene (PP) were experimentally tested under flexural loading. Inverse analysis was applied to obtain the used material properties of reinforced concrete by FEMIX software. After obtaining the material properties, to assess the performance of proposed slabs, some other cases were proposed and numerically evaluated under flexural and shear loading. The results showed that increasing steel fiber in reinforced entire cross section led to achieve better shear and flexural performance while the best performance of reinforced functionally graded slabs was achieved for slab at $1 \%$ fiber content. In the second stage, nineteen reinforced functionally graded RC slabs with steel bars were simulated and assessed and some other cases were considered which were not experimentally tested.

\section{Introduction}

Using fibrous materials leads to improve mechanical properties of concrete. Fibers transfer stresses after cracking of concrete by bridging action and, subsequently, ductility and load transferring are increased. In this direction, wide studies have been conducted to manifest different effects of various fibers in concrete reinforcement. The effective parameters on mechanical performance of reinforced concrete are type, geometry, and orientation and volume contents of used fibers in the matrix [1]. Using fibers in order to reinforce cementitious composites leads to enhance both toughness and mechanical strength [2]. In the last four decades wide studies have been conducted on the flexural behavior of FRCCs [3]. According to Figure 1, fibers are categorized into three groups which include (1) continuous fibers: long, straight, and generally layered-up parallel to each other; (2) chopped fibers: short and generally randomly distributed (fiberglass); (3) woven fibers: which come in cloth form and provide multidirectional strength.

According to material types, basic groups of fibers for using in the structural concrete are classified [4].

(i) Steel fibers with different shapes and dimensions, microfibers

(ii) Glass fibers, in cement matrices used only as alkaliresistant (AR) fibers

(iii) Synthetic fibers made with different materials: polypropylene, polyethylene and polyolefin, polyvinyl alcohol (PVA), and so forth

(iv) Carbon, pitch, and polyacrylonitrile (PAN) fibers.

In addition to type, geometry, mechanical properties of fibers, and bond behavior between fiber and matrix, some other effective parameters are exist which have influences on the responses of reinforced composites such as thickness 


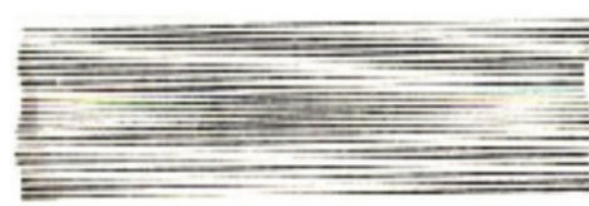

(a) Continuous fibers

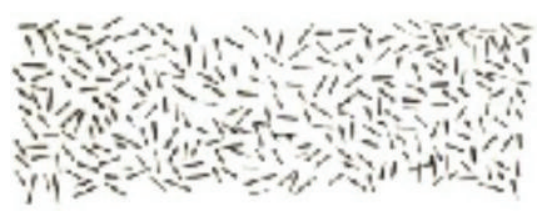

(b) Chopped fibers

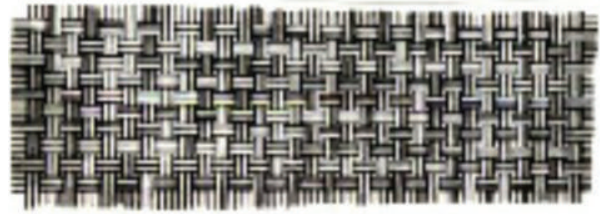

(c) Woven fibers

FIGURE 1: Various kinds of fibers which are used in FRC.

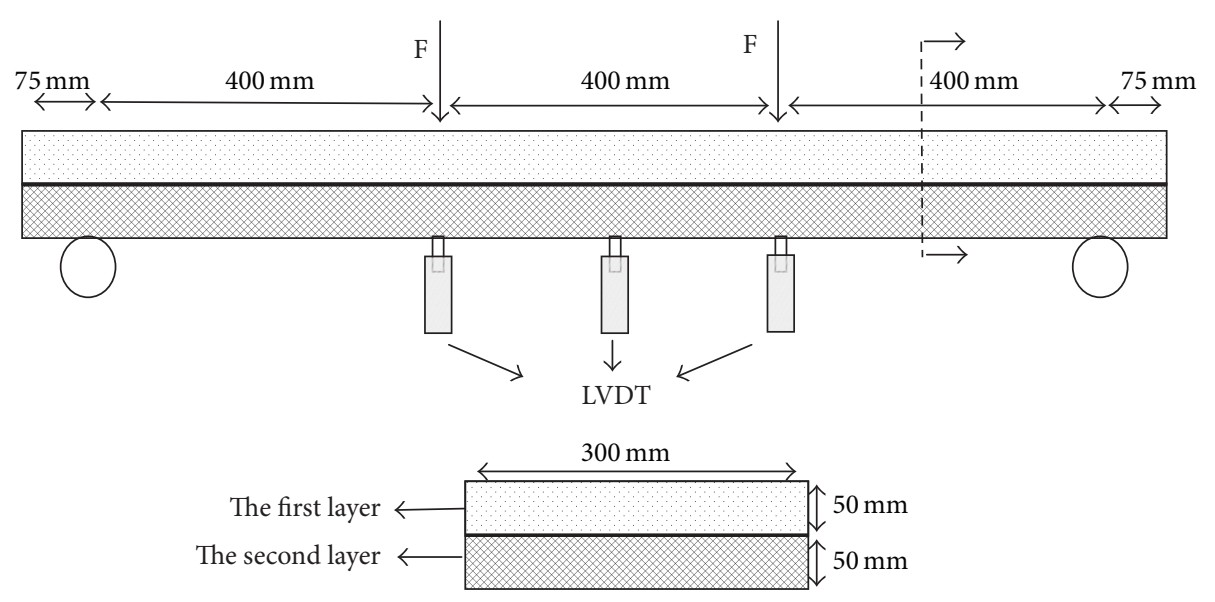

FIGURE 2: Schematic view of experimentally tested slabs.

of reinforced layers and circumstances of sorted reinforced composite layers. Nowadays, developing new techniques in rehabilitation applications results in increasing the importance of fiber reinforcement. Fiber reinforcement mechanism provides fiber bridging the micro-cracks that arrest the crack propagation, favoring the occurrence of large number of cracks of small width. Using reinforced concrete layers in enlargement sections is proposed as one of the new strengthening techniques for improving the flexural and shear performances. In this direction, the first stage of the present study was analytically assigned to evaluate the performances of functionally graded reinforced concrete slabs in both flexural and shear loadings and the performance of moment-curvature of each proposed slab was evaluated. The slabs were reinforced by steel and polypropylene (PP) fibers in different sorted reinforced concrete layers with $0.5 \%$, $1 \%$, and $2 \%$ fiber volume fractions. In the second stage, nineteen reinforced functionally graded RC slabs with steel bars were simulated and evaluated and some other cases were considered which were not experimentally tested. The aim of this study is achieving the best flexural performance of proposed slabs by using simulation in the most considerable cases for the proposed slabs. The main criteria to approach the best flexural performance of the proposed slabs were (1) load carrying capacity; (2) ductility; (3) fracture energy; (4) economic aspects.

\section{Unreinforced Functionally Graded RC Slabs with Steel Bars}

2.1. Simulated Experimental Slabs. Three unreinforced functionally graded RC slabs with steel bars were experimentally tested in [5] and numerical simulations were also calibrated based on the experimental results. Furthermore, some other cases were considered to be modeled which were eliminated due to economic aspects. The schematic view of tested slabs was shown in Figure 2 and three slabs were cast and tested which the top and bottom layers were reinforced by PP and steel fibers, respectively, with $0.5 \%, 1 \%$, and $2 \%$. The obtained experimental results were used to calibrate the numerical results.

The nomenclature of three tested slabs is listed in Table 1.

By calibrating three experimental results with numerical results in FEMIX software, other nine slabs were numerically simulated and evaluated under shear and flexural loading. 


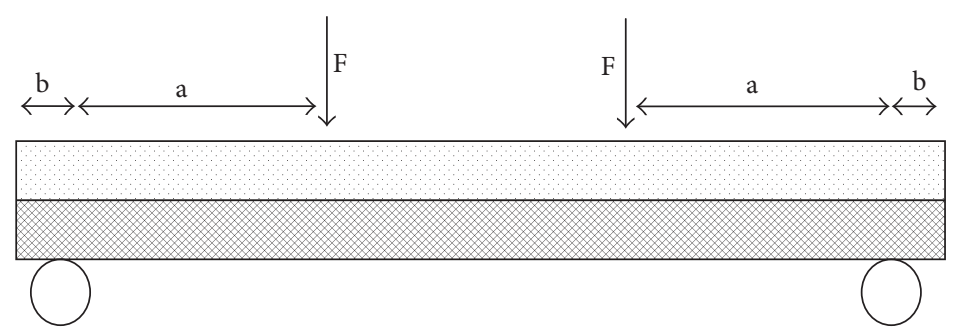

FIGURE 3: Schematic view of numerically simulated slabs.

TABLE 1: The nomenclature of experimentally tested slabs.

\begin{tabular}{lcccc}
\hline \multirow{2}{*}{ Slab name } & \multicolumn{2}{c}{ Type of used fiber } & \multicolumn{2}{c}{ Fiber content percent } \\
& Top & Bottom & Top & Bottom \\
\hline PS0.5 & PP & Steel & 0.5 & 0.5 \\
PS1 & PP & Steel & 1 & 1 \\
PS2 & PP & Steel & 2 & 2 \\
\hline
\end{tabular}

TABLE 2: The nomenclature and layer properties of numerically simulated slabs.

\begin{tabular}{lcccc}
\hline \multirow{2}{*}{ Slab name } & \multicolumn{2}{c}{ Type of used fiber } & \multicolumn{2}{c}{ Fiber content percent } \\
& Top & Bottom & Top & Bottom \\
\hline PS0.5 & PP & Steel & 0.5 & 0.5 \\
SP0.5 & Steel & PP & 0.5 & 0.5 \\
PP0.5 & PP & PP & 0.5 & 0.5 \\
SS0.5 & Steel & Steel & 0.5 & 0.5 \\
PS1 & PP & Steel & 1 & 1 \\
SP1 & Steel & PP & 1 & 1 \\
PP1 & PP & PP & 1 & 1 \\
SS1 & Steel & Steel & 1 & 1 \\
PS2 & PP & Steel & 2 & 2 \\
SP2 & Steel & PP & 2 & 2 \\
PP2 & PP & PP & 2 & 2 \\
SS2 & Steel & Steel & 2 & 2 \\
\hline
\end{tabular}

TABLE 3: The circumstances of applied loads for shear and flexural loadings.

\begin{tabular}{lcc}
\hline Type of loading & $a(\mathrm{~mm})$ & $b(\mathrm{~mm})$ \\
\hline Flexural & 400 & 75 \\
Shear & 50 & 75 \\
\hline
\end{tabular}

The position of each layer, used type, and content of fiber and the slab nomenclature are listed in Table 2. The circumstances of applied loads to evaluate slabs under shear and flexural loadings are mentioned in Table 3 and Figure 3.

\subsection{Numerical Simulations of Unreinforced Functionally} Graded RC Slabs with Steel Bars. Due economic aspects, the number of specimens available for investigation of the effects of double type reinforcement of the concrete is limited. Therefore for more through study, numerical approaches were applied. In the present work, multidirectional fixed smeared crack model was adopted, and the values of the constitutive model parameters were obtained considering the properties of the intervening materials. For performing this analysis, the mechanical properties of the materials were determined by inverse analysis. It has to be emphasized that the most important aspect of the numerical research carried out is the development of a very effective constitutive model for modeling beams failure in flexure with high accuracy. The numerical analysis has been carried out in two phases. In the first phase, by using inverse analysis, the mechanical properties of the beams completely reinforced by steel or PP fibers were found for different fiber volume fractions and subsequently the numerical models were calibrated with the experimental results for both reinforced and unreinforced functionally graded RC slabs with steel bars.

2.2.1. Multidirectional Fixed Smeared Crack Model. For analyzing the beams in finite element methods (FEM), the beams were considered by plane stress problem. The explanation of the formulation of the multidirectional fixed smeared crack model is related to the case of cracked concrete, at the domain of an integration point (IP). According to the adopted constitutive law for plane stress finite element, stress and strain are related to each other by

$$
\Delta \sigma=D^{\mathrm{Crcon}} \Delta \varepsilon
$$

where $\Delta \sigma=\left\{\Delta \sigma_{1}, \Delta \sigma_{2}, \Delta \tau_{12}\right\}^{T}$ and $\Delta \varepsilon=\left\{\Delta \varepsilon_{1}, \Delta \varepsilon_{2}, \Delta \gamma_{12}\right\}^{T}$ are the components of stress and strain vectors, respectively. By decomposing the total strain in (1) into elastic and cracked concrete parts, that is, $\Delta \varepsilon=\Delta \varepsilon^{\text {ela }}+\Delta \varepsilon^{\text {cra }}, D^{\text {Crco }}$ can be obtained by Naghibdehi et al. $[5,6]$ as follows:

$$
\begin{aligned}
D^{\mathrm{Crco}}= & D^{\mathrm{Co}}-D^{\mathrm{Co}}\left[T^{\mathrm{Cr}}\right]^{T} \\
& \times\left(D^{\mathrm{Cr}}+T^{\mathrm{Cr}} D^{\mathrm{Co}}\left[T^{\mathrm{Cr}}\right]^{T}\right)^{-1} T^{\mathrm{Cr}} D^{\mathrm{Co}},
\end{aligned}
$$

where $D^{\mathrm{Co}}$ is the constitutive matrix of concrete which is assumed to have a linear behavior as follows:

$$
D^{\mathrm{Co}}=\frac{E_{c}}{1-v_{C}^{2}}\left[\begin{array}{ccc}
1 & v_{c} & 0 \\
v_{c} & 1 & 0 \\
0 & 0 & \frac{1-v_{c}}{2}
\end{array}\right],
$$

in which $E_{c}$ and $v_{C}$ are elasticity modulus and Poisson's ratio of concrete, respectively. In (2), $T^{\mathrm{Cr}}$ is the transform matrix 
TABLE 4: Properties adopted to simulate the nonlinear behavior.

\begin{tabular}{|c|c|c|c|c|c|c|c|c|c|c|c|c|}
\hline & \multirow{2}{*}{ PP0.5 } & \multirow{2}{*}{ PP1 } & \multirow{2}{*}{ PP2 } & \multirow{2}{*}{ SS0.5 } & \multirow{2}{*}{ SS1 } & \multirow{2}{*}{ SS2 } & \multicolumn{2}{|c|}{ PS0.5 and SP0.5 } & \multicolumn{2}{|c|}{ PS1 and SP1 } & \multicolumn{2}{|c|}{ PS2 and SP2 } \\
\hline & & & & & & & $\mathrm{PP}$ & SS & PP & SS & $\mathrm{PP}$ & SS \\
\hline Poisson's ratio $\left(v_{c}\right)$ & 0.15 & 0.15 & 0.15 & 0.15 & 0.15 & 0.15 & \multicolumn{2}{|c|}{0.15} & \multicolumn{2}{|c|}{0.15} & \multicolumn{2}{|c|}{0.15} \\
\hline Initial Young's modulus (GPa) & 18.42 & 18.42 & 18.42 & 18.42 & 18.42 & 18.42 & 18.42 & 18.42 & 18.42 & 18.42 & 15 & 15 \\
\hline Compressive strength (MPa) & 49.36 & 55.5 & 45.27 & 46.91 & 68.44 & 69.32 & 49.36 & 46.9 & 49.36 & 46.9 & 49.36 & 46.9 \\
\hline $\begin{array}{l}\text { Maximum number of cracks in } \\
\text { an integration point (IP) }\end{array}$ & 2 & 2 & 2 & 2 & 2 & 2 & \multicolumn{2}{|r|}{2} & \multicolumn{2}{|c|}{2} & \multicolumn{2}{|c|}{2} \\
\hline $\begin{array}{l}\text { Parameter defining the mode I } \\
\text { fracture energy available to the } \\
\text { new crack }\left(P_{1}\right)\end{array}$ & 2 & 2 & 2 & 2 & 2 & 2 & \multicolumn{2}{|r|}{2} & \multicolumn{2}{|c|}{2} & \multicolumn{2}{|c|}{2} \\
\hline $\begin{array}{l}\text { Shear retention factor } \\
\text { (exponential) }\end{array}$ & 2 & 2 & 2 & 2 & 2 & 2 & \multicolumn{2}{|r|}{2} & \multicolumn{2}{|c|}{2} & \multicolumn{2}{|c|}{2} \\
\hline Crack band-width, $l_{\text {cr }}$ & $\sqrt{ } \mathrm{Ai}$ & $\sqrt{ } \mathrm{Ai}$ & $\sqrt{ } \mathrm{Ai}$ & $\sqrt{ } \mathrm{Ai}$ & $\sqrt{ } \mathrm{Ai}$ & $\sqrt{ } \mathrm{Ai}$ & \multicolumn{2}{|r|}{$\sqrt{ } \mathrm{Ai}$} & \multicolumn{2}{|c|}{$\sqrt{ } \mathrm{Ai}$} & \multicolumn{2}{|c|}{$\sqrt{ } \mathrm{Ai}$} \\
\hline Threshold angle $\alpha_{\text {th }}$ & 30 & 30 & 30 & 30 & 30 & 30 & \multicolumn{2}{|r|}{30} & \multicolumn{2}{|c|}{30} & \multicolumn{2}{|c|}{30} \\
\hline
\end{tabular}

of stress components from the coordinate system of element to local crack coordinate system. If $n$ is the number of cracks, $T^{\mathrm{Cr}}$ is defined as

$$
T^{\mathrm{Cr}}=\left[T_{1}^{\mathrm{Cr}} \ldots T_{i}^{\mathrm{Cr}} \ldots T_{n}^{\mathrm{Cr}}\right]^{T}
$$

where the crack orientation matrix is given by

$$
T_{i}^{\mathrm{Cr}}=\left[\begin{array}{ccc}
\cos ^{2} \theta & \sin ^{2} \theta & 2 \sin \theta \cos \theta \\
-\sin \theta \cos \theta & \sin \theta \cos \theta & \cos ^{2} \theta-\sin ^{2} \theta
\end{array}\right],
$$

where $\theta$ is defined as the angle between the $x_{1}$ axis and the vector orthogonal to the plane of the $i$ th crack. Furthermore, $D^{\mathrm{Co}}$ in (2) is defined as a matrix that includes the constitutive law of the $n$ cracks as follows:

$$
D^{\mathrm{Cr}}=\left[\begin{array}{ccccc}
D_{1}^{\mathrm{Cr}} & \cdots & 0 & \cdots & 0 \\
\cdots & \cdots & \cdots & \cdots & \cdots \\
0 & \cdots & D_{i}^{\mathrm{Cr}} & \cdots & 0 \\
\cdots & \cdots & \cdots & \cdots & \cdots \\
0 & \cdots & 0 & \cdots & D_{n}^{\mathrm{Cr}}
\end{array}\right]
$$

In the above equation, $D_{i}^{\mathrm{Cr}}$ is the crack constitutive matrix of the $i$ th crack which is defined as

$$
D^{\mathrm{Cr}}=\left[\begin{array}{cc}
D_{\mathrm{I}, i}^{\mathrm{Cr}} & 0 \\
0 & D_{\mathrm{II}, i}^{\mathrm{Cr}}
\end{array}\right] \text {, }
$$

where $D_{\mathrm{I}, i}^{\mathrm{Cr}}$ and $D_{\mathrm{II}, i}^{\mathrm{Cr}}$ are the moduli corresponding to the fracture mode I (normal) and fracture mode II (shear) of the $i$ th crack, respectively. In this numerical approach, a new crack forms in an integration point (IP) when the angle between the new crack and the already existing cracks exceeds a certain threshold angle (this angle is selected between 30-60 degrees according to [7]). The crack opening propagation was simulated using the trilinear diagram which is indicated in Figure 4. Normalized stresses $(\beta$ and $\zeta)$ and strains $(\alpha$ and $\lambda)$ were defined and used for transposition points between the linear segments of the diagram. The ultimate crack strain $\left(\varepsilon_{n}^{\mathrm{Cr}}\right)$ is governed by the fracture energy,

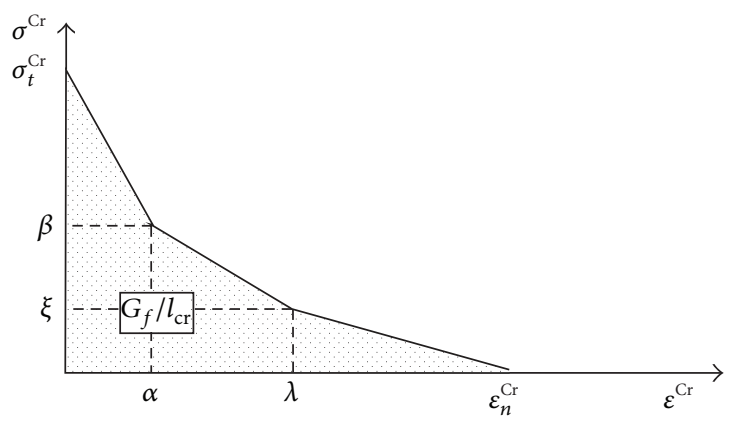

$\alpha=$ The strain at the first postpeak point/the ultimate strain $\xi=$ The stress at the second postpeak point/the tensile strength $\beta=$ The stress at the first postpeak point/the tensile strength $\lambda=$ The strain at the second postpeak point/the ultimate strain

FIgURE 4: Trilinear stress-strain diagram to simulate the fracture mode I crack propagation.

tensile strength $\left(\sigma_{t}^{\mathrm{Cr}}\right)$, crack band width $\left(l_{\mathrm{Cr}}\right)$, and normalized strains and stresses. Hence, the ultimate crack strain is given by Sena-Cruz [8] as follows:

$$
\varepsilon_{n}^{\mathrm{Cr}}=\frac{2}{\alpha+\beta \lambda-\xi \alpha+\xi}\left(\frac{G_{f}}{l_{\mathrm{Cr}} \sigma_{t}^{\mathrm{Cr}}}\right),
$$

and the fracture mode II modulus, $D_{\mathrm{II}}^{\mathrm{Cr}}$, is defined by Barras et al. [9] as follows:

$$
D_{\mathrm{II}}^{\mathrm{Cr}}=\frac{\kappa}{1-\kappa} G_{C}
$$

where $G_{C}$ is the elastic concrete shear modulus and $\kappa$ is the shear retention factor. The parameter $\kappa$ is considered to be a function of the current crack normal strain $\left(\varepsilon_{\mathrm{Cr}}\right)$ and ultimate crack normal strain $\left(\varepsilon_{n}^{\mathrm{Cr}}\right)$ [9], given by

$$
\kappa=\left(1-\frac{\varepsilon^{\mathrm{Cr}}}{\varepsilon_{n}^{\mathrm{Cr}}}\right)^{P_{1}} .
$$


TABLE 5: Values defining the tensile softening diagram for functionally graded reinforced concrete, obtained from inverse analysis.

\begin{tabular}{lcccccccc}
\hline Multilayers & Layer positions & Crack strength $(\mathrm{MPa})$ & $\alpha$ & $B$ & $\lambda$ & $\xi$ & Fracture energy (Gf) \\
\multirow{2}{*}{ PS0.5 } & PP0.5 & 1.28 & 0.1 & 0.45 & 0.5 & 1.2 & 1.55 \\
& SS0.5 & 1.38 & 0.15 & 0.6 & 0.5 & 1.05 & 2.05 \\
\hline \multirow{2}{*}{ PS1 } & PP1 & 2.1 & 0.1 & 0.9 & 0.8 & 0.8 & 1.06 \\
& SS2 & 2.2 & 0.15 & 1.4 & 0.8 & 0.7 & 2.11 \\
\hline \multirow{2}{*}{ PS2 } & PP2 & 2.7 & 0.1 & 0.8 & 0.7 & 0.3 & 1 \\
& SS2 & 2.85 & 0.15 & 0.88 & 0.7 & 0.4 & 1.8 \\
\hline
\end{tabular}
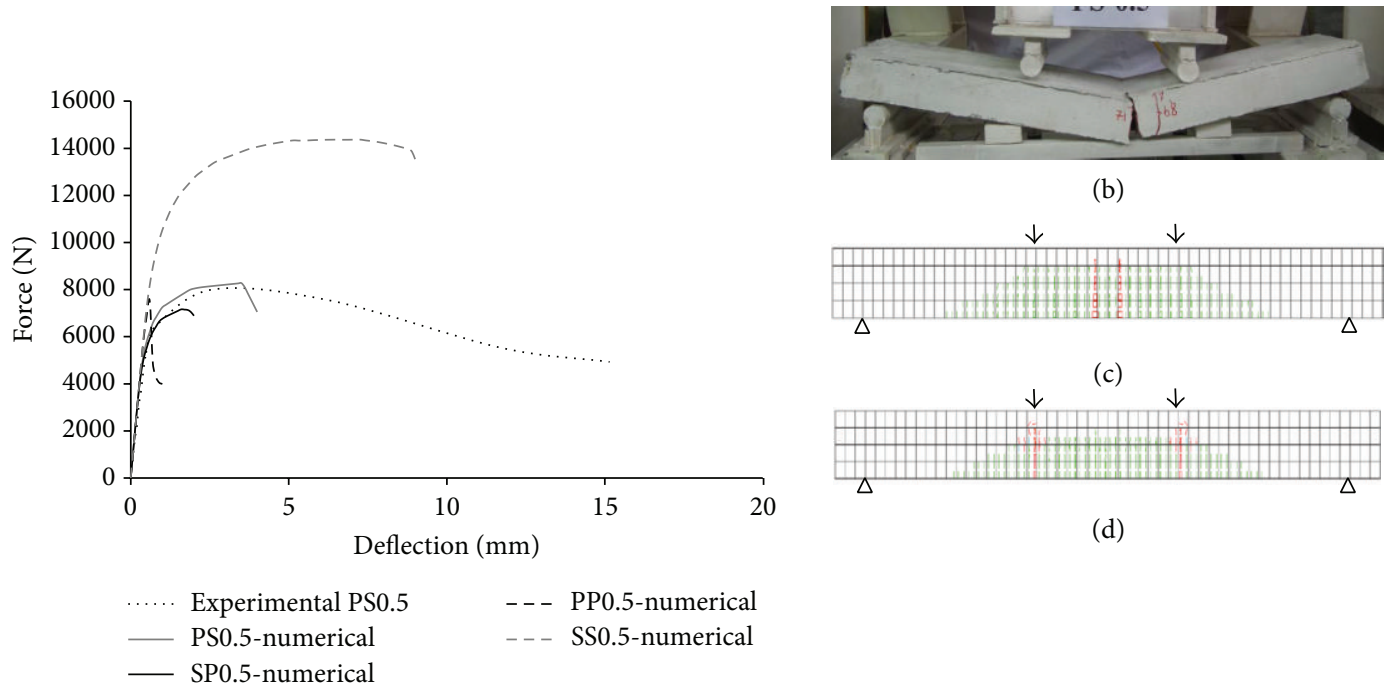

(b)

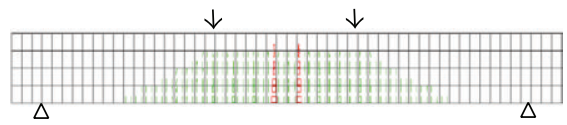

(c)

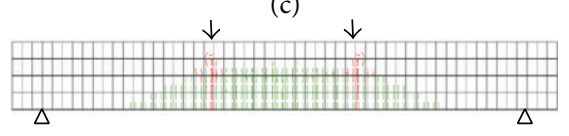

(d)

(a)

FiguRE 5: (a) Flexural responses of calibrated and proposed cases of reinforced slab with $0.5 \%$ fiber content; (b) experimentally tested slab PS0.5; (c) formed crack pattern of simulated slab PS0.5; (d) formed crack pattern of simulated slab SP0.5.

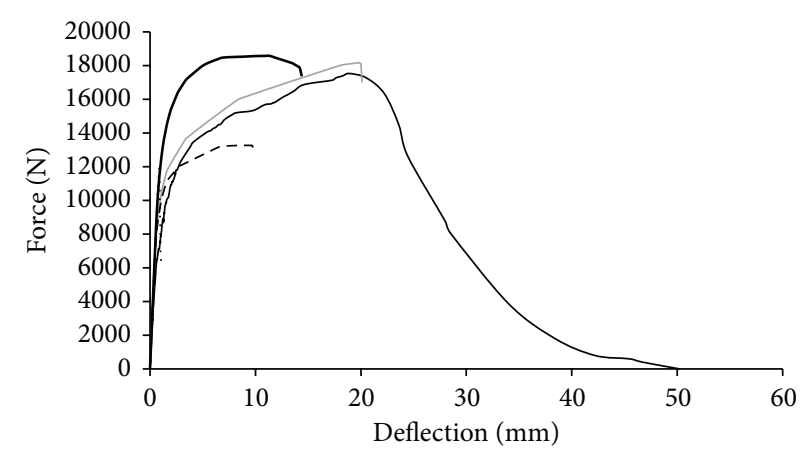

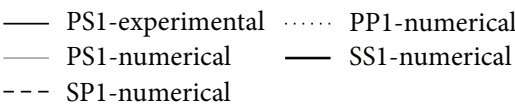

(a)

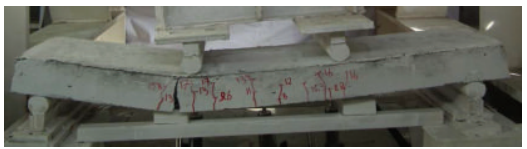

(b)

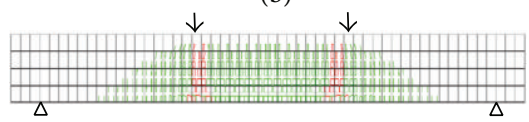

(c)

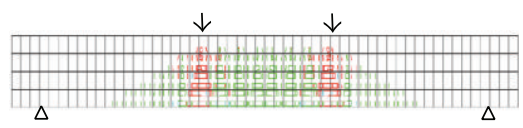

(d)

(c) formed crack pattern of simulated slab PS1; (d) formed crack pattern of simulated slab SP1. 

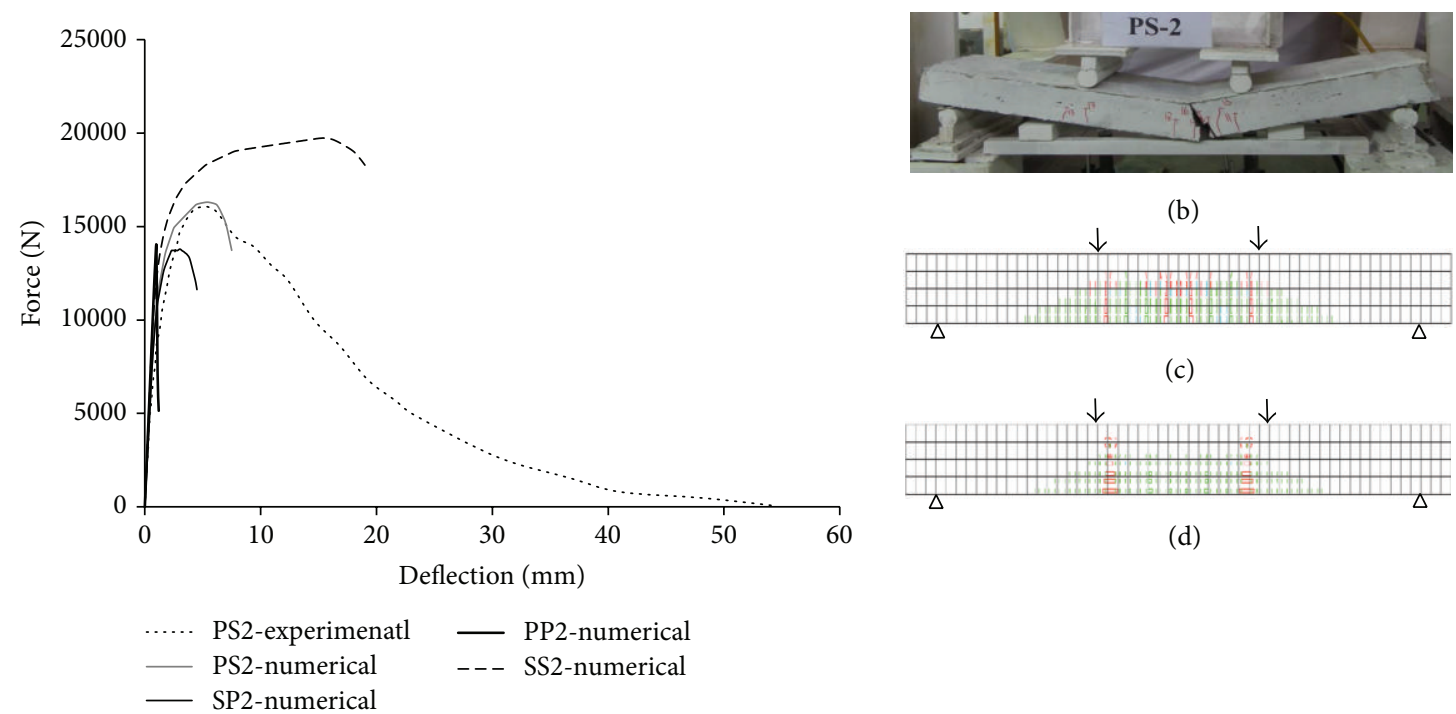

(b)

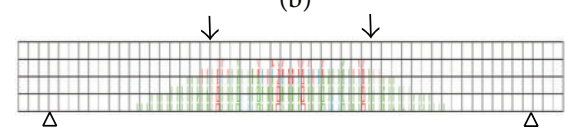

(c)

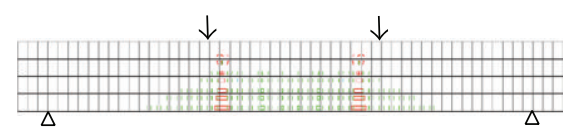

(d)

(a)

FIGURE 7: (a) Flexural responses of calibrated and proposed cases of reinforced slab with 2\% fiber content; (b) experimentally tested slab PS2; (c) formed crack pattern of simulated slab PS2; (d) formed crack pattern of simulated slab SP2.

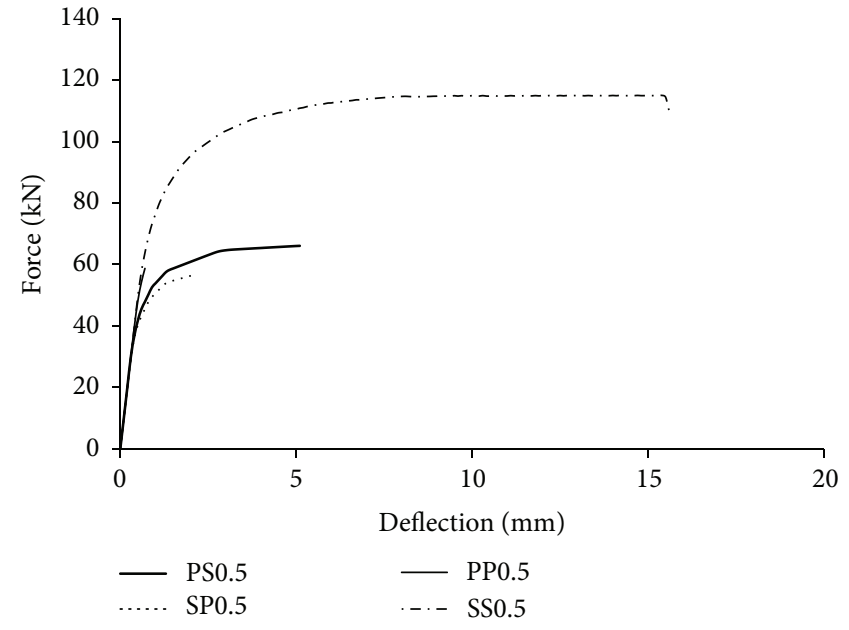

(a)

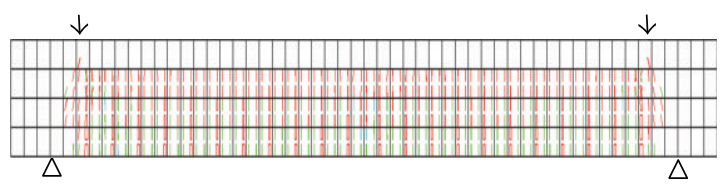

(b)

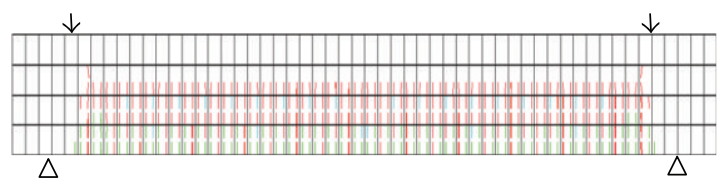

(c)

Figure 8: (a) Shear responses of reinforced slab with 0.5\% fiber content; (b) formed crack pattern of simulated slab PS0.5; (c) formed crack pattern of simulated slab SP0.5.

If $P_{1}=1, \kappa$ decreases linearly as $\varepsilon_{n}^{\mathrm{Cr}}$ increases. Higher values of the exponent result in more decrease in the parameter of $\kappa$ [8]. To analyze the specimens, the considered values for proposed components were listed in Table 4. To simulate the material, the compressive strength is required. Hence, some compressive tests were conducted on the materials and obtained values are given in Table 4 .

2.2.2. Inverse Analysis. To determine the values of the parameters that define the fracture mode I propagation, an inverse analysis was performed using the force-deflection relationship obtained in the flexural tests of slabs.
The specimens were modeled in FEMIX computer program using the properties given in Table 4. Plane stress serendipity elements of 8 nodes, with $2 \times 2$ Gauss-Legendre integration scheme, were used in the numerical simulations.

By conducting inverse analysis of the specimens, the obtained parameters for fracture mode I such as the obtained crack strength, fracture energy, normalized stresses, and strains were listed in Table 5. Furthermore, the calibrated experimental and numerical flexural responses of forcedeflection relationship for slabs SP0.5, SP1, and SP2 and other considered numerical simulated cases are shown in Figures 5-7 and are subsequently listed in Table 5. According to Figures 5-7, the calibrated numerical and experimental 

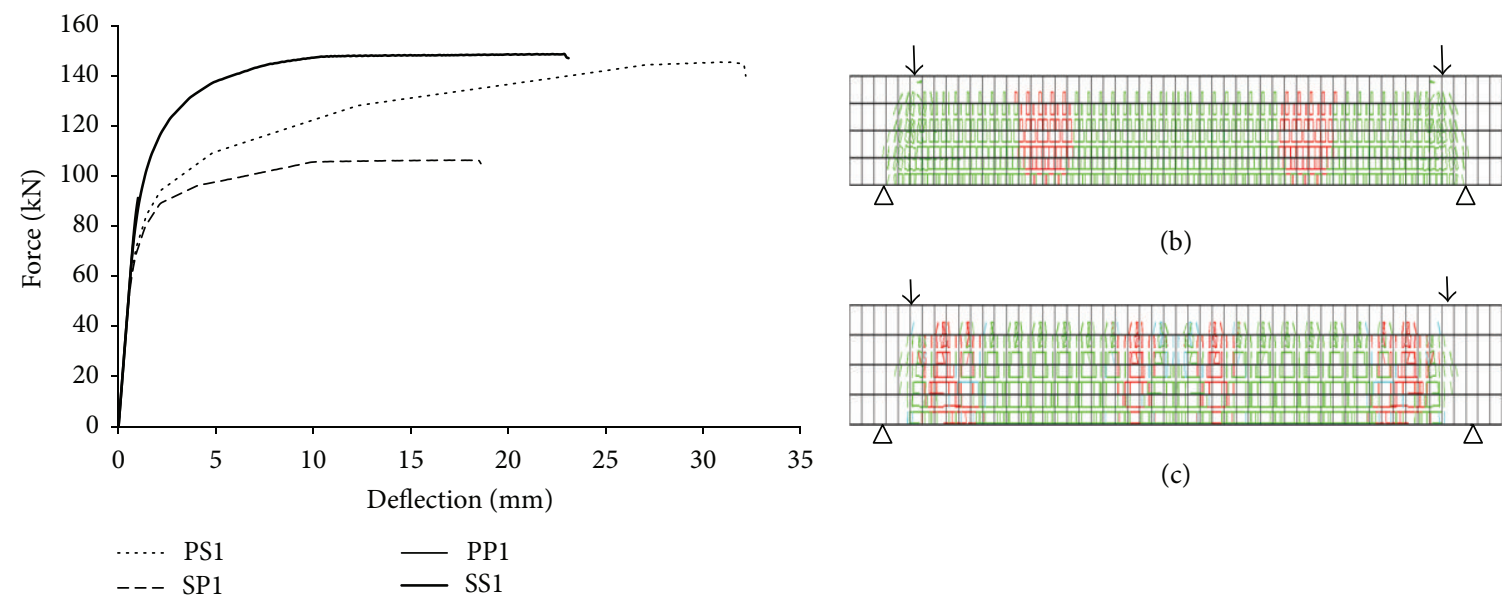

(b)

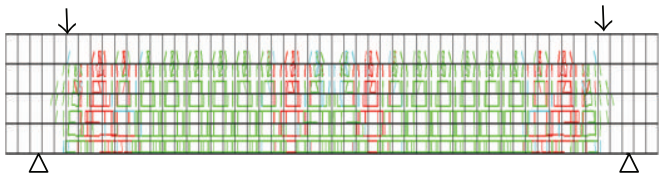

(c)

(a)

FIGURE 9: (a) Shear responses of reinforced slab with 1\% fiber content; (b) formed crack pattern of simulated slab PS1; (c) formed crack pattern of simulated slab SP1.
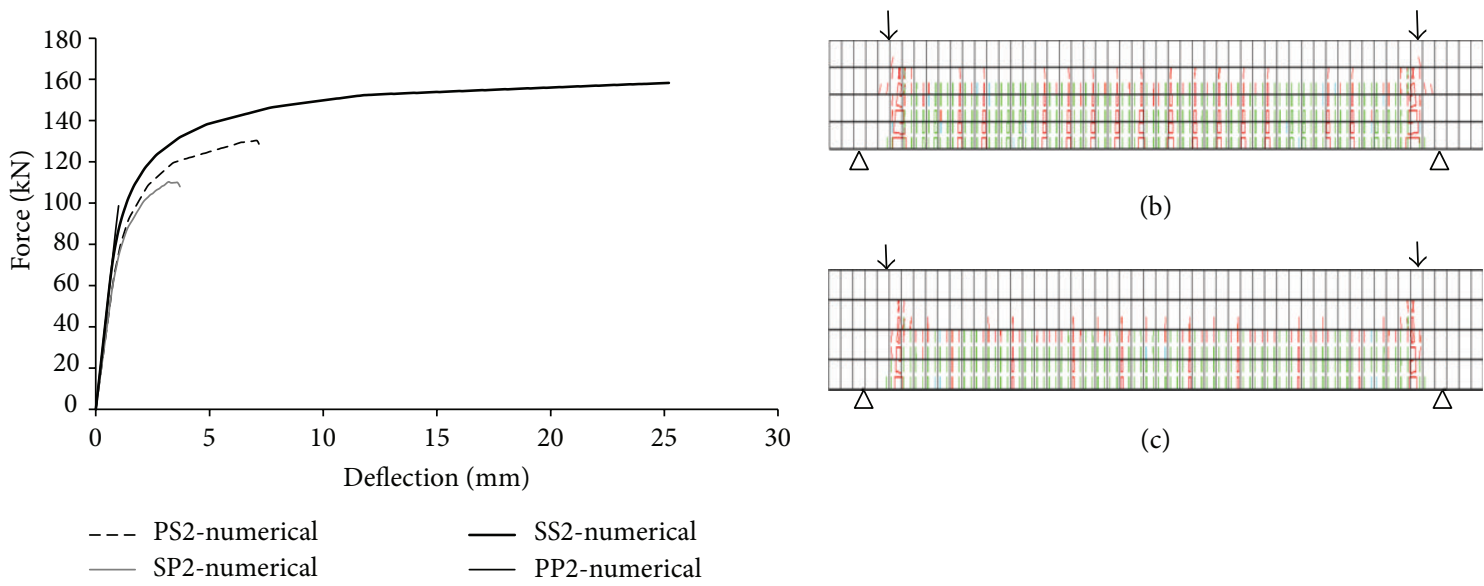

(b)

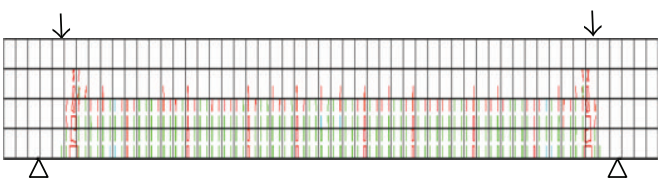

(c)

(a)

Figure 10: (a) Shear responses of reinforced slab with 2\% fiber content; (b) formed crack pattern of simulated slab PS2; (c) formed crack pattern of simulated slab SP2.

results have good agreement which illustrates high accuracy of modeling slabs with very effective constitutive model. It is worth mentioning that the obtained parameters of fracture mode I for slabs under flexural loading were used to evaluate the slab behaviors under shear loading.

The crack patterns are represented in Figures 5, 6, and 7 in which the red, cyan, and green colors represent the cracks in opening, reopening, and closing processes, respectively. Furthermore, the calibrated flexural responses are used to evaluate the slabs under shear loads. Therefore, the slabs based on the defined material properties and loading conditions in Tables 5 and 3 were evaluated for shear performance and the results are shown in Figures 8, 9, and 10.

\section{Results and Discussions of Unreinforced Functionally Graded RC Slabs with Steel Bars}

According to the obtained analytical results of slabs in both shear and flexural loadings, some issues were discussed. By focusing on the force of initial cracks and maximum force in Figure 11, for both flexural and shear, it is revealed that increasing fiber content has various effects on the reinforced slabs.

Increasing fiber content led to increasing the initial force crack in all specimens under flexural loading while the maximum applied force in the all slabs was increased except 


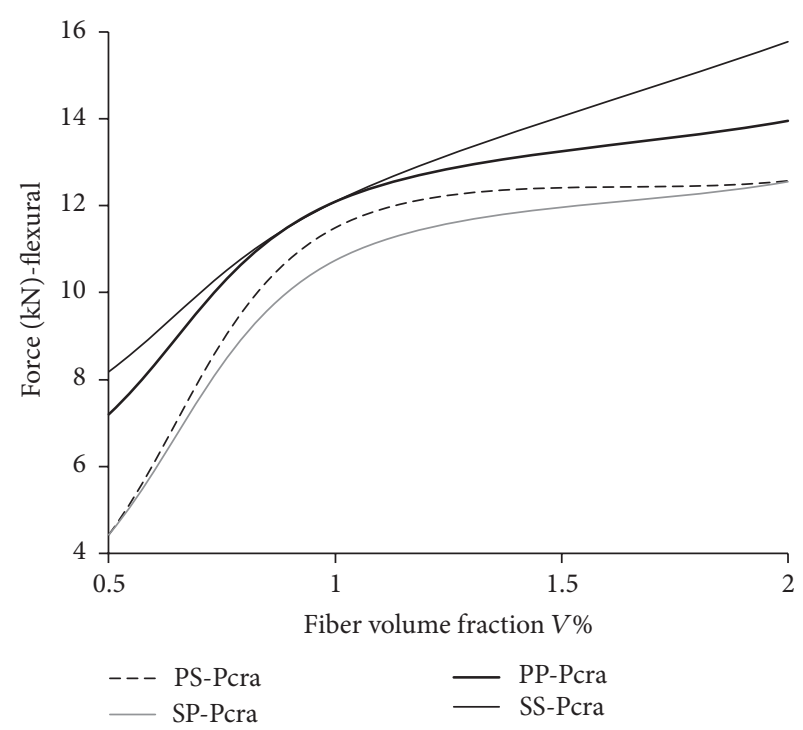

(a)

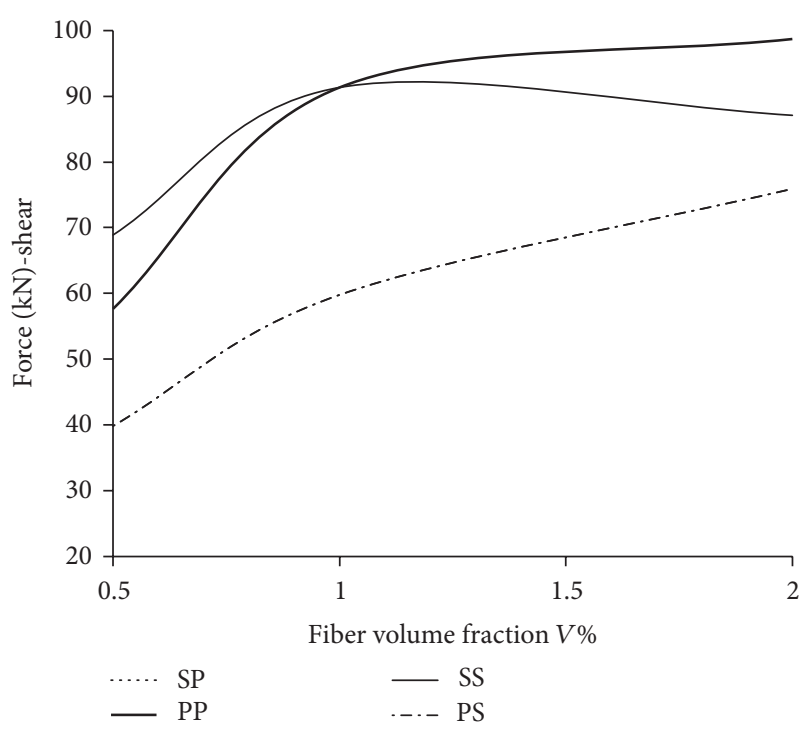

(c)

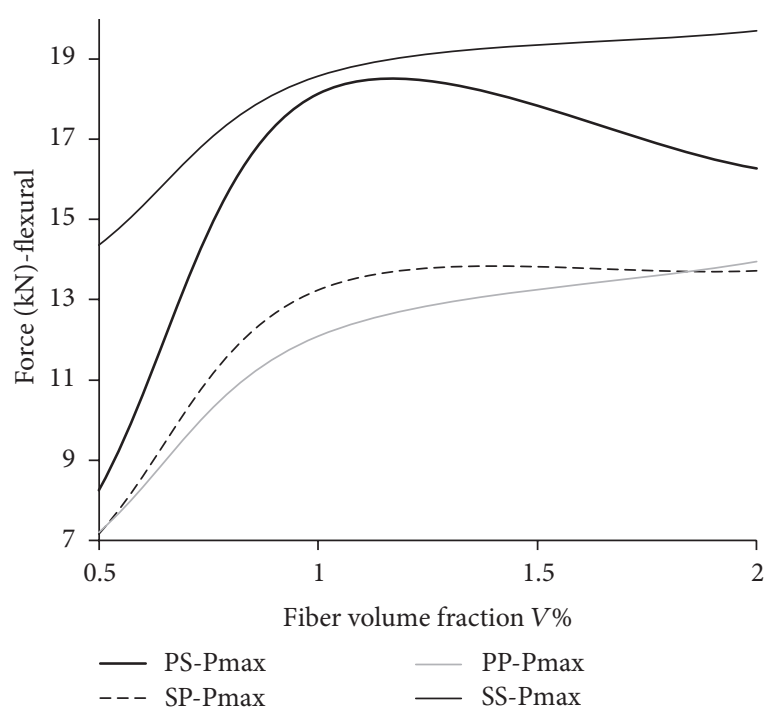

(b)

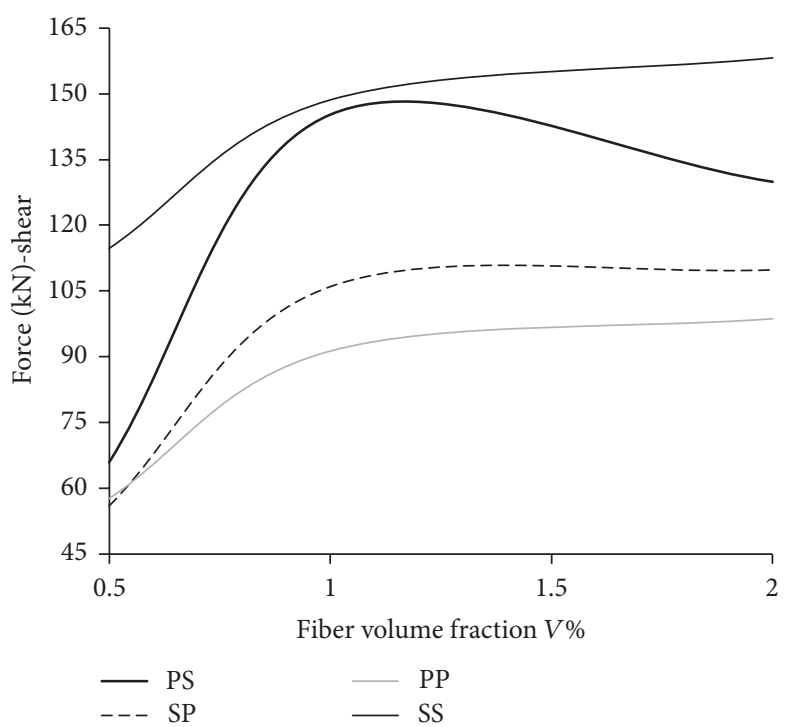

(d)

FIGURE 11: (a) Variations of the initial force crack due to different fiber content under flexural loading; (b) variations of the maximum applied load due to different fiber content under flexural loading; (c) variations of the initial force crack due to different fiber content under shear loading; (d) variations of the maximum applied load due to different fiber content under shear loading.

specimen PS. The maximum applied load in the specimen PS with $2 \%$ fiber content decreased $11.48 \%$ in comparison to reinforced slab with $1 \%$. Furthermore, it was interesting that increasing fiber content had the same effects on increasing $47.49 \%$ the initial force crack of specimens SP and PS under shear loading while the maximum applied force were not increased in both SP and PS slabs.

The maximum applied load in shear was increased $49.01 \%$ in specimen SP at $2 \%$ fiber content in comparison to $0.5 \%$ while this value was decreased $11.78 \%$ in specimen PS with $2 \%$ fiber volume fraction in comparison to $1 \%$. Increasing fiber content led to increase $41.56 \%$ both the initial force crack and the maximum applied load for reinforced slabs with PP fiber. Since, increasing fiber content led to decrease $4.85 \%$ in reinforced slabs with steel fiber at $2 \%$ fiber volume fraction in comparison to $1 \%$ and increase $27.46 \%$ the maximum applied load for reinforced slabs with steel fiber at $2 \%$ fiber volume fraction in comparison to $0.5 \%$.

Figure 12 illustrated the effects of circumstances of sorted reinforced concrete layers on the ultimate to service limit state applied force ratio and ductility under flexural loading. The results demonstrated that using functionally graded reinforced concrete led to increase $23.98 \%$ and $37.78 \%$ in the ultimate applied force in comparison to service limit state force, while the ultimate applied force in the entire reinforced cross section with steel fiber was constant from $2 \%$ to $1 \%$ fiber 


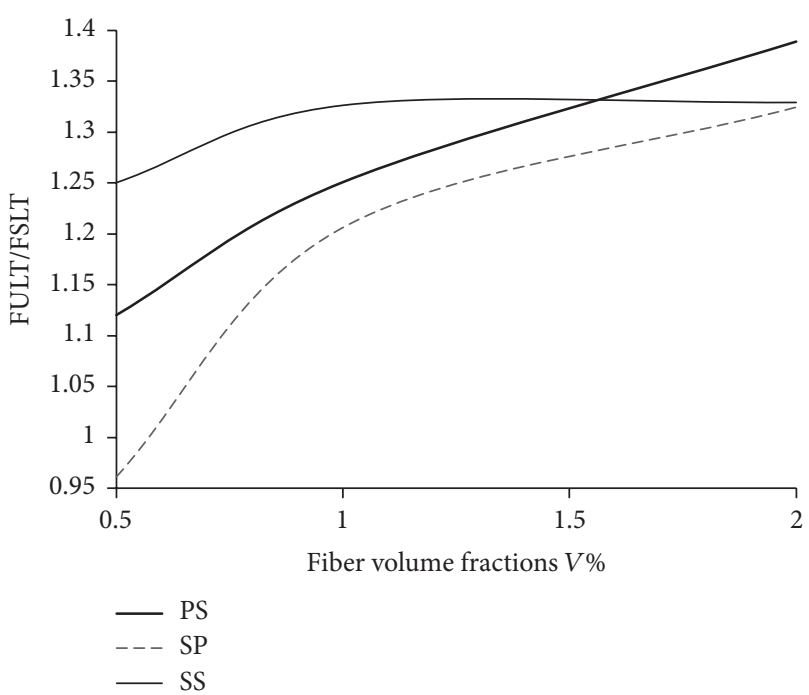

(a)

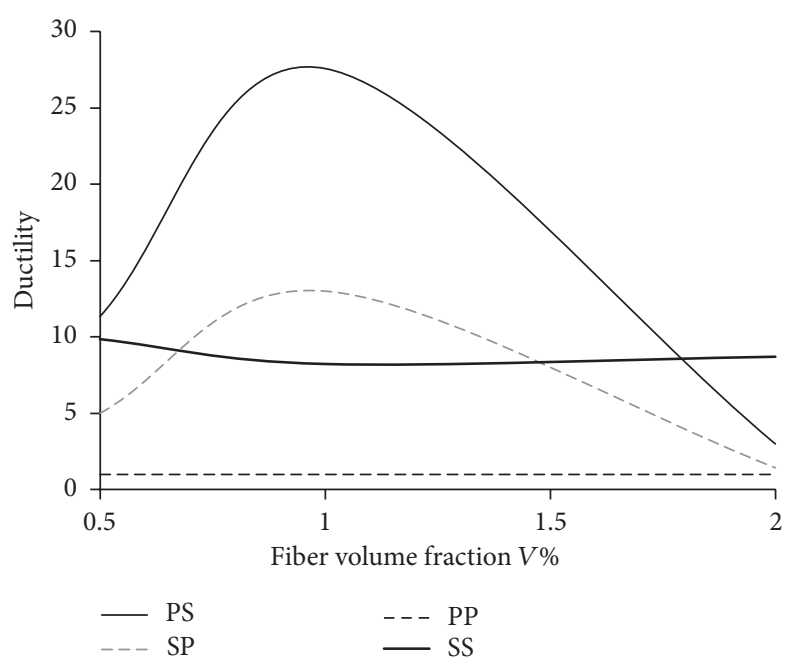

(b)

FIGURE 12: (a) Variations of ultimate to service limit state force ratio due to fiber volume fraction variations; (b) effects of fiber content variations on the ductility.

volume content. Furthermore, the ductility was achieved to its highest value at $1 \%$ fiber volume fraction (about 28 times) in the functionally graded reinforced concrete. Ductility in the entire reinforced cross section with PP fiber was the minimum value which illustrates inability of this type of fiber to enhance ductility of slab as well as increasing steel fiber content not only increased the ductility, but also decreased $19.76 \%$ ductility by increasing $0.5 \%$ to $1 \%$ fiber volume fraction.

Assuming that a plane section remains plane after bending, and shear deformation of the section can be ignored, the moment-curvature $(M-\chi)$ diagram can be obtained. By applying bending moment on a section of a slab, the curvature of section can be determined by dividing the top compressive strain by the depth of neutral axis. A cross section is discretized in layers that can have distinct constitutive laws for the characterization of the behavior of the materials that constitute these layers. The moment curvature of slabs by considering different reinforced layer properties and positions of each layer was achieved in the DOCROS software and the obtained moment curvature curves and the curvature ductility of slabs were shown in the Figure 13. According to Figure 13, reinforcement of slab by using $0.5 \%$ steel fiber content led to increase averagely $75.4 \%$ yielding moment (My) in comparison to other slabs. According to the obtained results in the previous parts, the reinforcement of slabs by usage of PP fiber led to decrease ductility and more brittleness observed in comparison to other proposed slabs. Hence, the reinforcement effects of slabs by using PP fiber led to obtain almost the similar yielding moment and the plastic moment. Thus, by changing fiber content, the increased yielding moment at $2 \%$ fiber volume content was increased 2.4 times and $37.36 \%$ in comparison to $0.5 \%$ and $1 \%$ fiber content, respectively. Furthermore, by increasing fiber volume content from $0.5 \%$ to $1 \%$, the yielding moment was increased $20.44 \%$ and $75.97 \%$ for specimens PS and SP, respectively, while the plastic moment was increased $32.39 \%$ and $51.02 \%$. By considering the curvature ductility, the entire reinforced cross section was slightly affected by fiber volume fraction variations while the slabs SP and PS were significantly influenced. The curvature ductility responses for slabs SP and PS were completely different. The curvature ductility in the slab PS was achieved to its maximum value at $1 \%$ fiber volume fraction and increased about $33 \%$ in comparison to $0.5 \%$ fiber content whereas the curvature ductility was decreased about 5.5 times at $2 \%$ fiber content in comparison to $1 \%$. This phenomenon led to obtain the highest ductility in the slab PS in comparison to others as well as the formed crack numbers in both experimental and numerical simulation demonstrates the accuracy of obtained curvature ductility variations due to reinforcement of concrete by utilizing various fiber volume content. Since then, the maximum curvature ductility in the slab SP was obtained at $0.5 \%$ fiber content and increased 6.33 and 3.64 times in comparison to $1 \%$ and $2 \%$ fiber content, respectively.

\section{Reinforced Functionally Graded RC Slabs with Steel Bars}

4.1. Experimental Program. The second phase of this paper has been assigned to simulate nineteen experimentally tested functionally graded RC slabs based on [6] under flexural loading. The nomenclature and properties of nineteen simulated slabs were listed in Table 6. And the layer positions were illustrated in Figure 14. The reinforced slabs with steel bars were prepared according to ACI code [10]. The design details, the used steel reinforcements, and layer positions were shown in Figure 14. Furthermore, the mechanical properties of the used steel bars are listed in Tables 7 and 8 . The dimension 


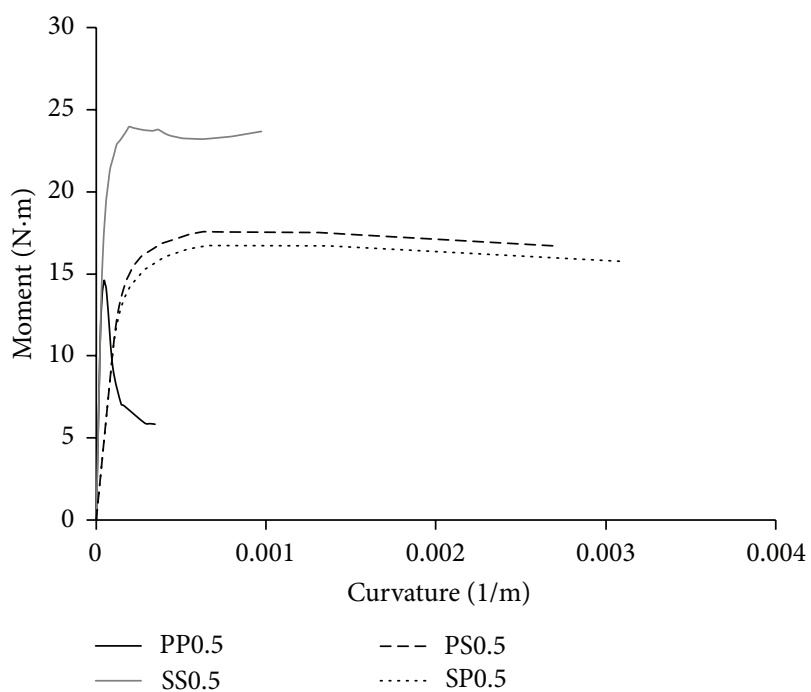

(a)

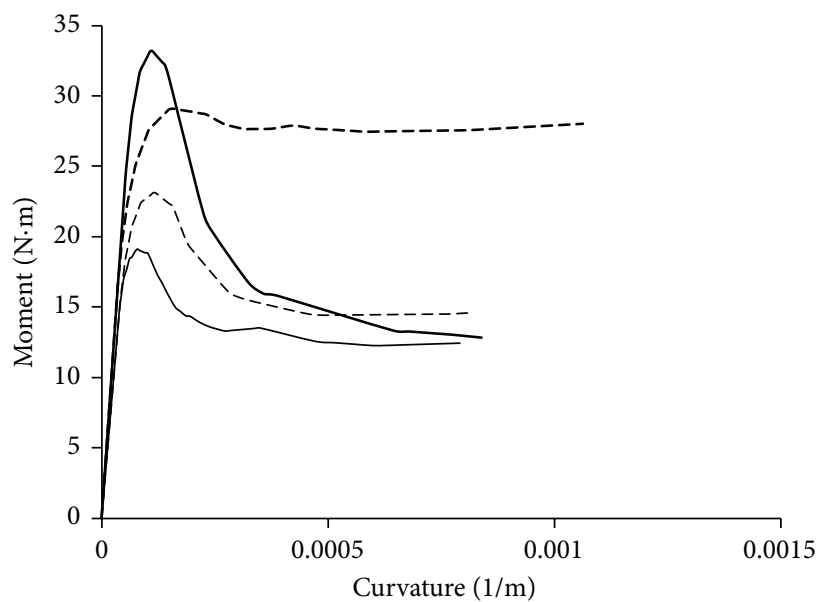

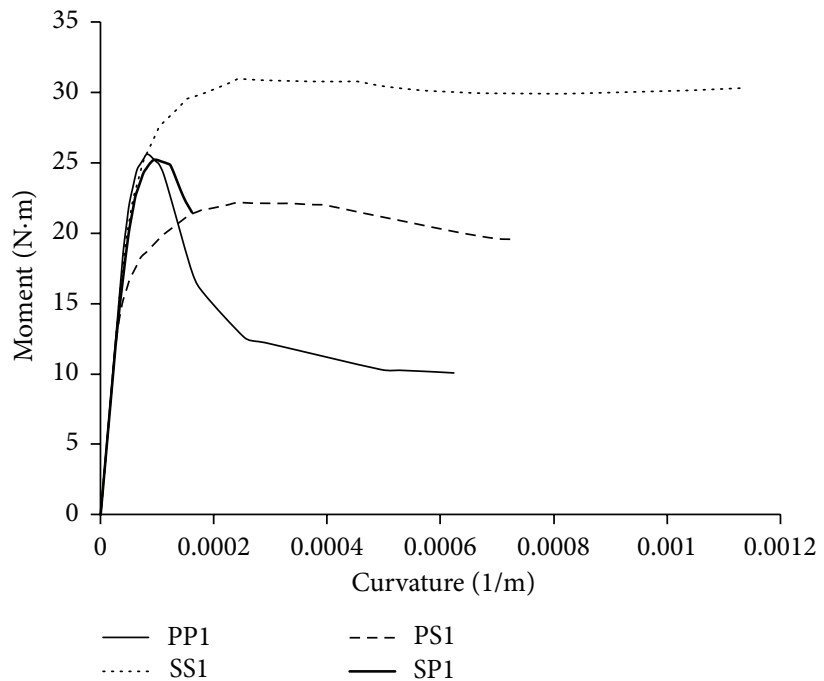

(b)

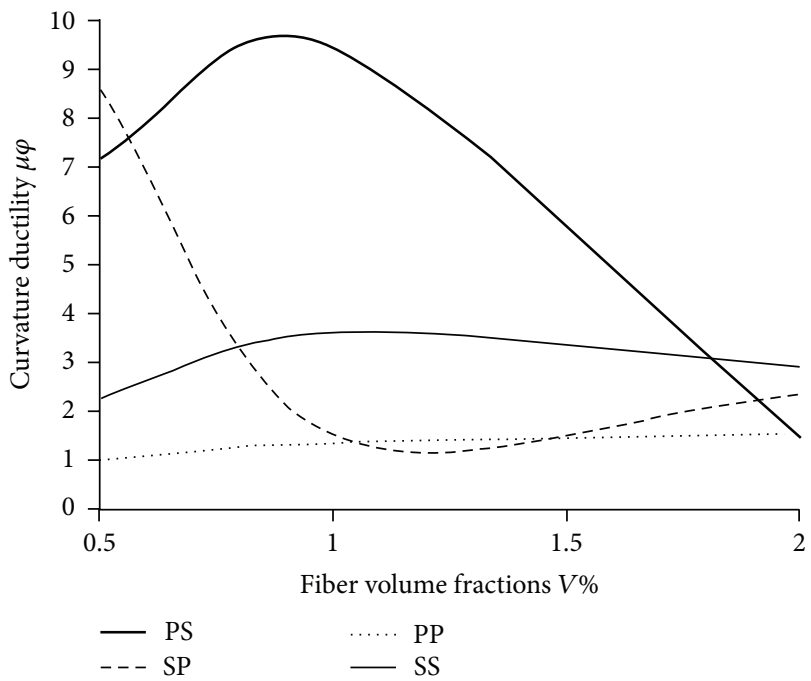

(d)

Figure 13: (a) Moment-curvature for reinforced slab with 0.5\% fiber content; (b) moment-curvature for reinforced slab with $1 \%$ fiber content; (c) moment-curvature for reinforced slab with $2 \%$ fiber content; (d) fiber content effects on curvature ductility.

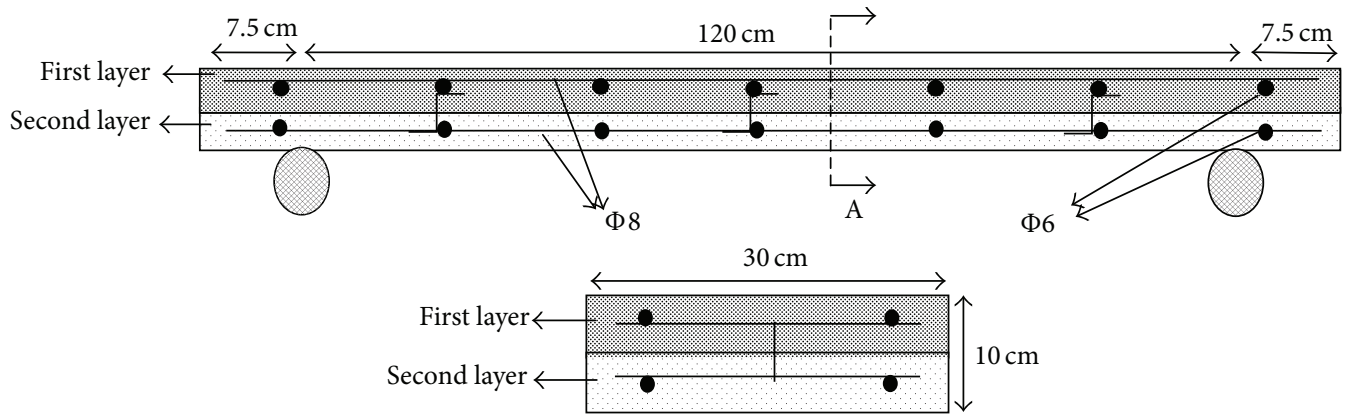

FIGURE 14: Reinforced functionally graded RC slab with steel bars. 
TABLE 6: The nomenclature and properties of reinforced functionally graded RC slabs with steel bars.

\begin{tabular}{|c|c|c|c|c|c|c|c|c|}
\hline \multirow{3}{*}{ Number of specimen } & \multirow{3}{*}{ Name of specimen } & \multicolumn{6}{|c|}{ Type of layer concrete } & \multirow{3}{*}{ Volume fraction of fiber in $\mathrm{RC}(\%)$} \\
\hline & & \multicolumn{3}{|c|}{ Upper layer } & \multicolumn{3}{|c|}{ Bottom layer } & \\
\hline & & PPFRC & SFRC & $\mathrm{NC}$ & PPFRC & SFRC & $\mathrm{NC}$ & \\
\hline 1 & SNN & & & $\checkmark$ & & & $\checkmark$ & 0 \\
\hline 2 & SNP 0.5 & & & $\checkmark$ & $\checkmark$ & & & 0.5 \\
\hline 3 & SNP 1 & & & $\checkmark$ & & $\checkmark$ & & 1 \\
\hline 4 & SNP 2 & & & $\checkmark$ & & $\checkmark$ & & 2 \\
\hline 5 & SPN 0.5 & $\checkmark$ & & & & & $\checkmark$ & 0.5 \\
\hline 6 & SPN 1 & $\checkmark$ & & & & & $\checkmark$ & 1 \\
\hline 7 & SPN 2 & $\checkmark$ & & & & & $\checkmark$ & 2 \\
\hline 8 & SNS 0.5 & & & $\checkmark$ & & $\checkmark$ & & 0.5 \\
\hline 9 & SNS 1 & & & $\checkmark$ & & $\checkmark$ & & 1 \\
\hline 10 & SNS 2 & & & $\checkmark$ & & $\checkmark$ & & 2 \\
\hline 11 & SSN 0.5 & & $\checkmark$ & & & & $\checkmark$ & 0.5 \\
\hline 12 & SSN 1 & & $\checkmark$ & & & & $\checkmark$ & 1 \\
\hline 13 & SSN 2 & & $r$ & & & & $\checkmark$ & 2 \\
\hline 14 & SPP 0.5 & $\checkmark$ & & & $\checkmark$ & & & 0.5 \\
\hline 15 & SPP 1 & $\checkmark$ & & & $\checkmark$ & & & 1 \\
\hline 16 & SPP 2 & $r$ & & & $\checkmark$ & & & 2 \\
\hline 17 & SSS 0.5 & & $\checkmark$ & & & $\checkmark$ & & 0.5 \\
\hline 18 & SSS 1 & & $\checkmark$ & & & $\checkmark$ & & 1 \\
\hline 19 & SSS 2 & & $\checkmark$ & & & $\checkmark$ & & 2 \\
\hline
\end{tabular}

TABLE 7: The usage purpose and position of used steel reinforcements.

\begin{tabular}{|c|c|c|c|}
\hline Steel reinforcement type & Length $(\mathrm{cm})$ & Usage & Location \\
\hline$\Phi 8$ & 130 & Longitudinal reinforcement (tensile) & Bottom \\
\hline \multirow{4}{*}{$\Phi 6$} & 25 & Shrinkage and temperature reinforcement & Bottom \\
\hline & 130 & Shrinkage and temperature reinforcement & Top \\
\hline & 25 & Shrinkage and temperature reinforcement & Top \\
\hline & 12 & Connector for two layers & Between top and bottom layers \\
\hline
\end{tabular}

and test setup of the reinforced slabs with steel bars were chosen the same as the unreinforced slabs. According to BS EN 1992-1-1, the normal concrete can be classified C45/55 [11]. Furthermore, the used steel bars are categorized to AI and AII based on Iranian Concrete Code for $\Phi 6$ and $\Phi 8$, respectively $[12,13]$.

The longitudinal steel bars were modeled with 2-noded perfect bonded embedded cables (one degree-of-freedom per each node). For modeling the behavior of the longitudinal and transversal steel bars, the stress-strain relationship represented in Figure 15 was adopted. The curve (under compressive or tensile loading) is defined by the points PT1 $=($ esy, rsy $)$, PT2 $=($ esh, rsh $)$, and PT3 = (esu, rsu $)$ and a parameter $p$ that defines the shape of the last branch of the curve. Unloading and reloading linear branches with slope Es $=$ rsy/esy are assumed in the present approach.

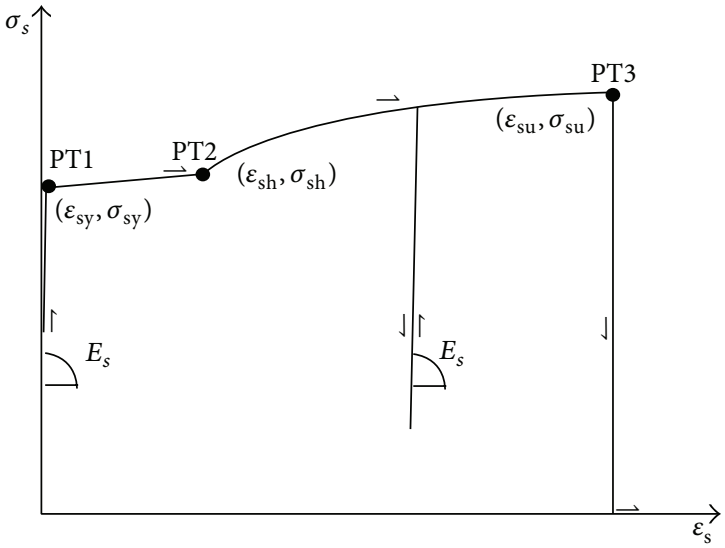

FIGURE 15: Uniaxial constitutive model for the steel bars [13]. 


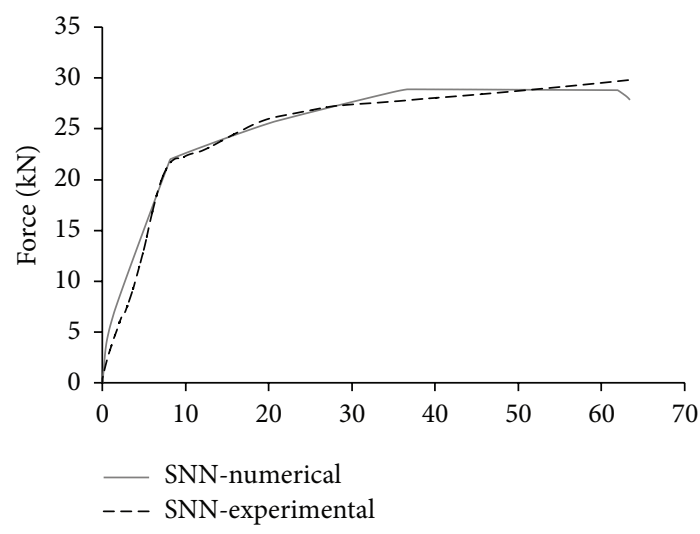

(a)

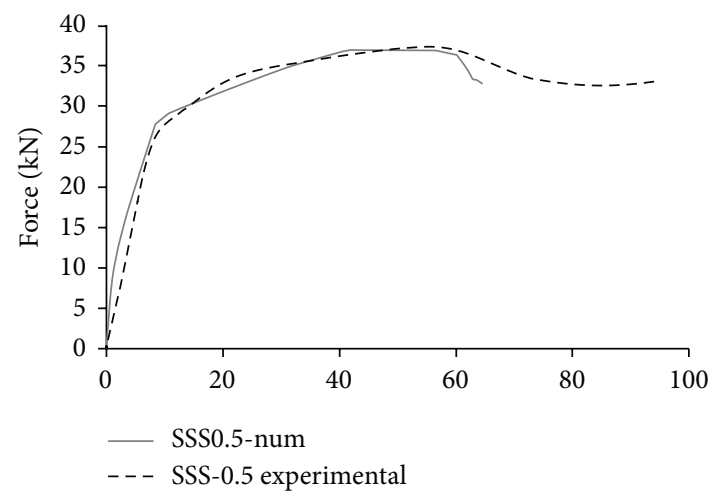

(c)

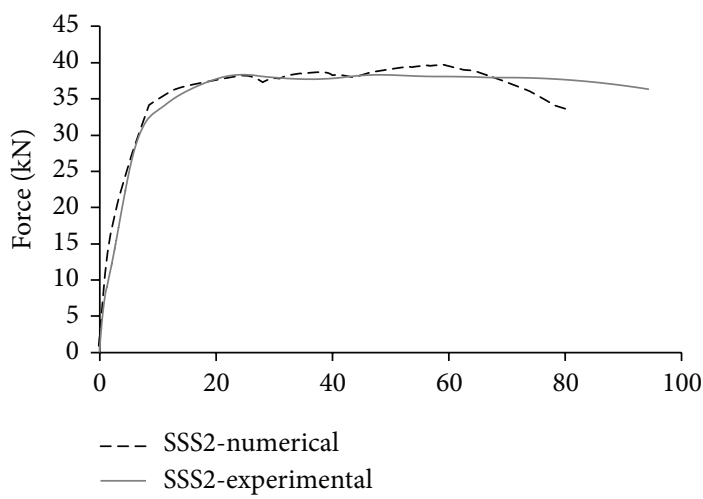

(e)

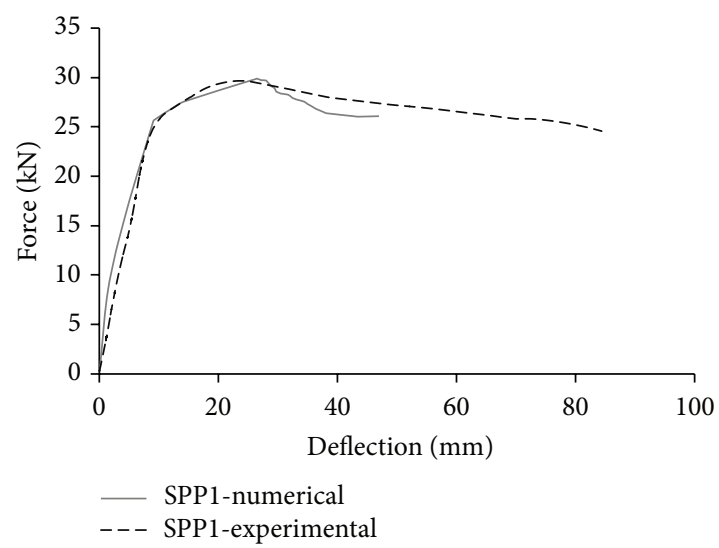

(g)

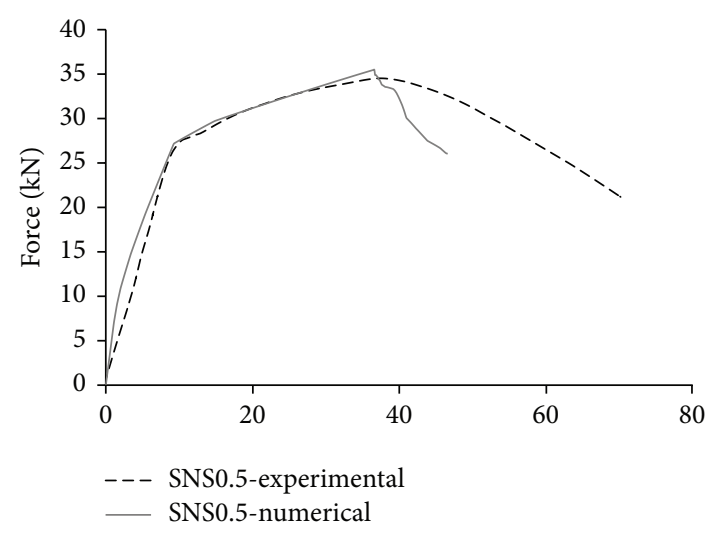

(b)

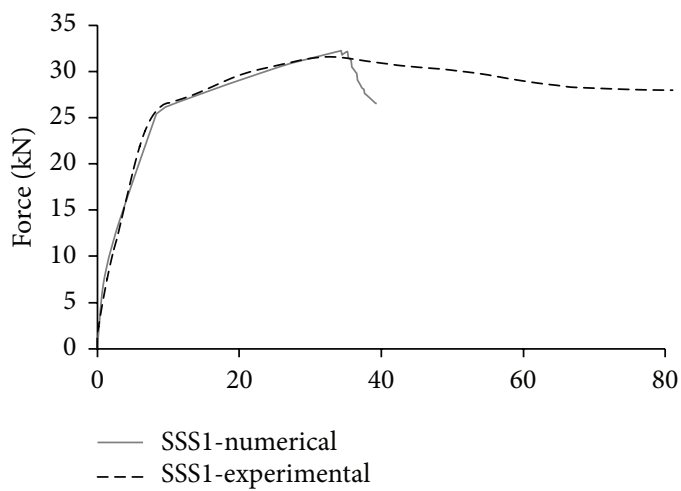

(d)

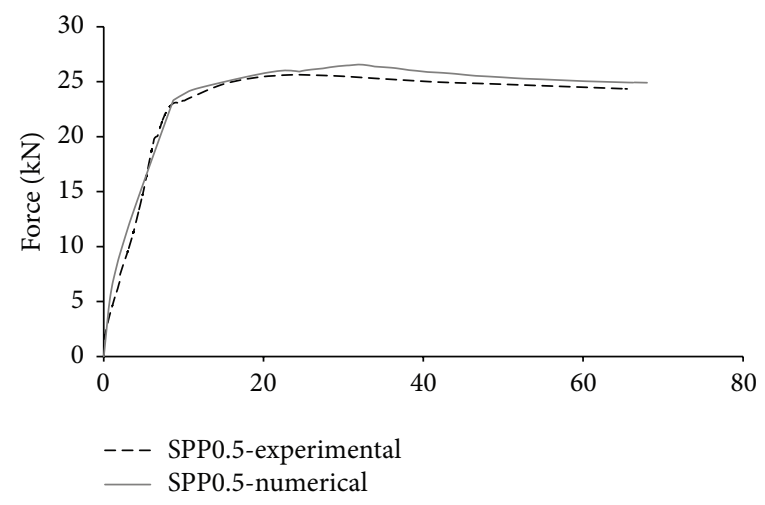

(f)

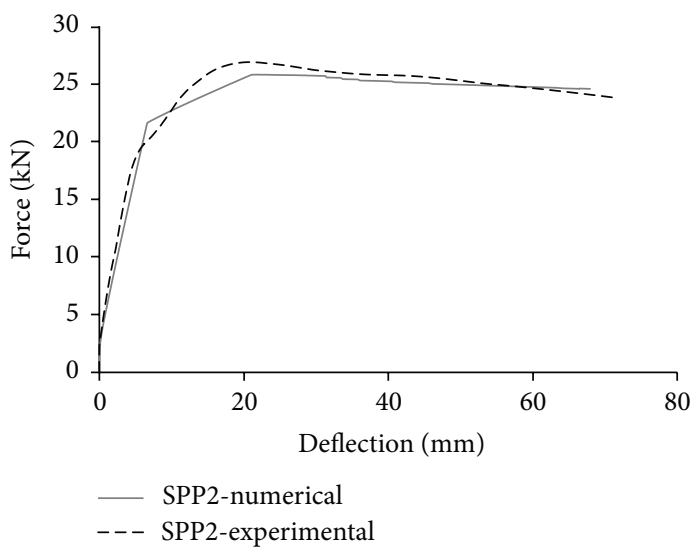

(h)

FIgURE 16: Continued. 


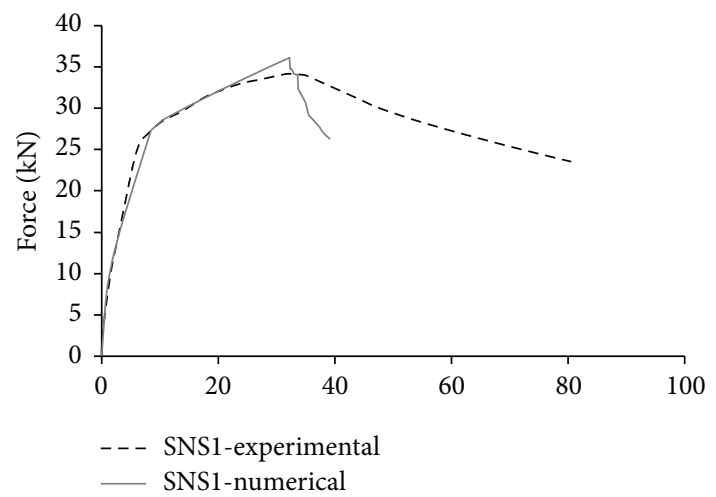

(i)

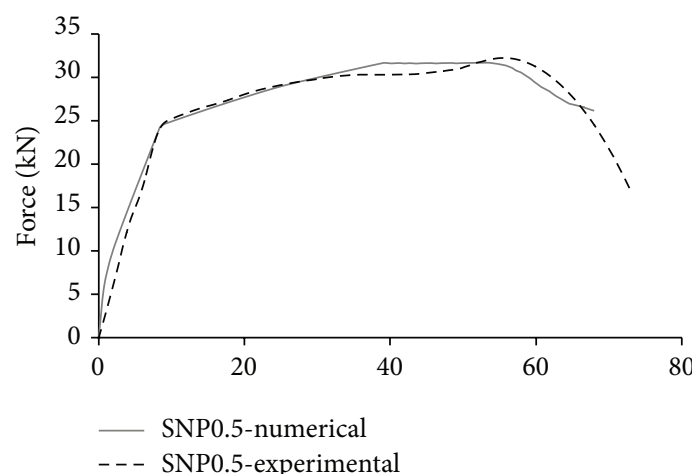

(k)

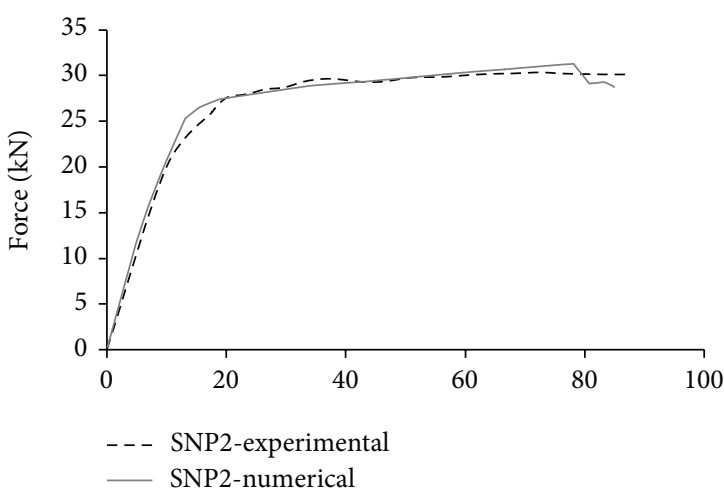

(m)

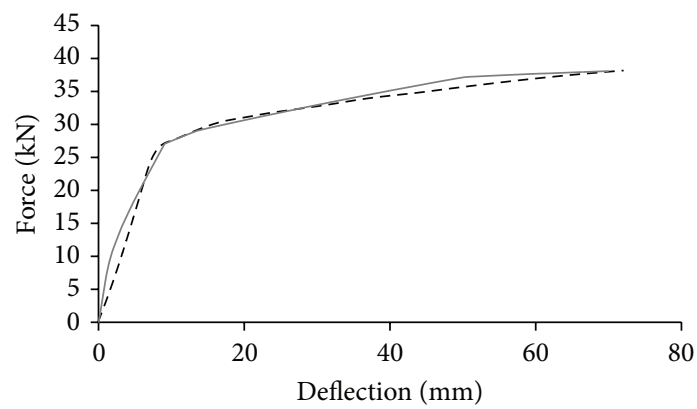

SN1-experimental

SSN1-numerical

(o)

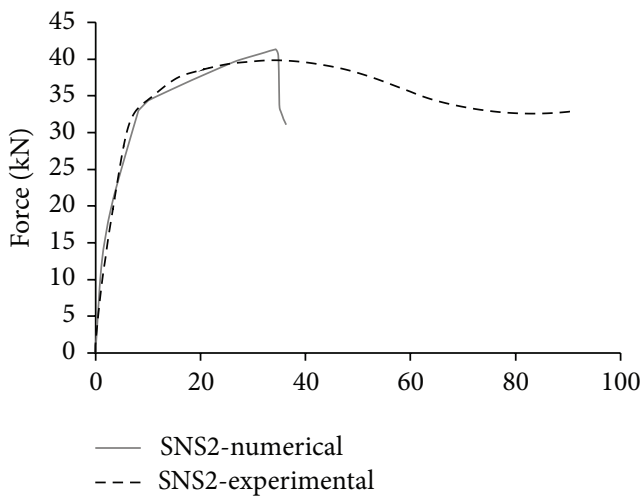

(j)

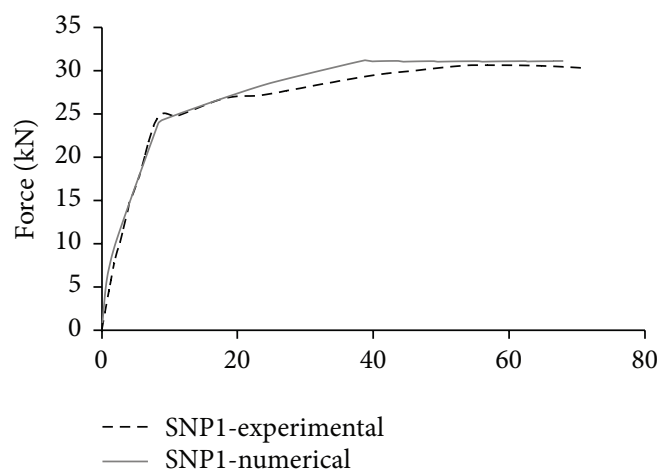

(l)

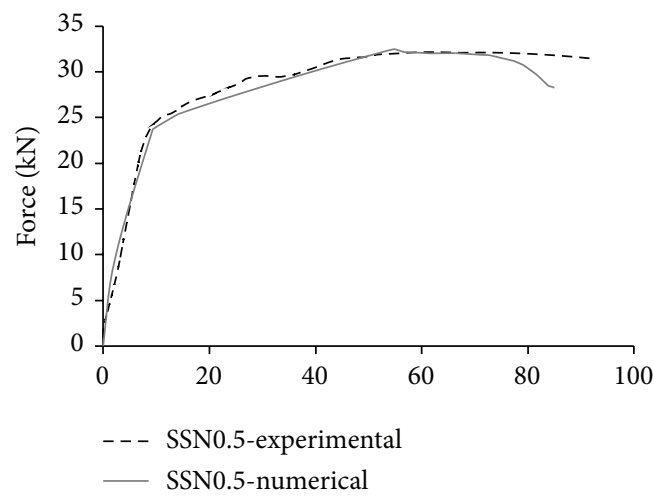

(n)

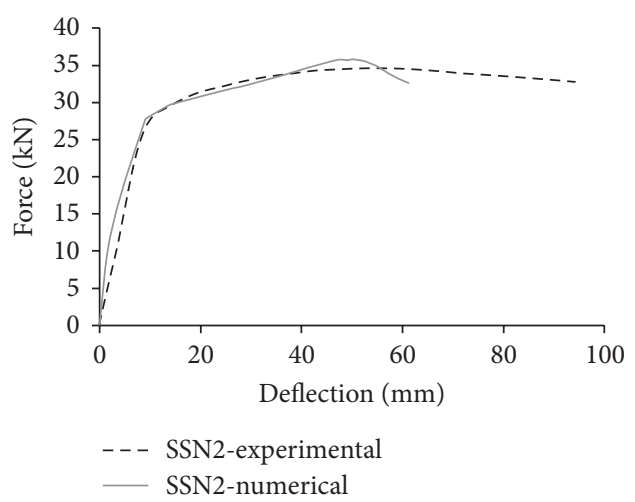

(p)

FIgUre 16: Continued. 


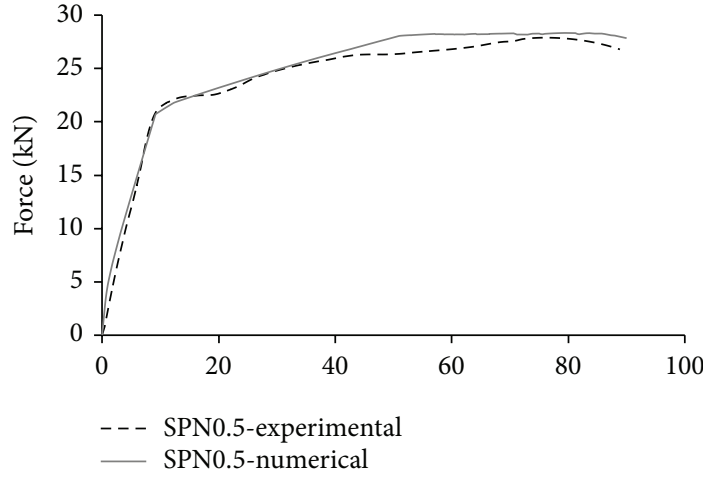

(q)

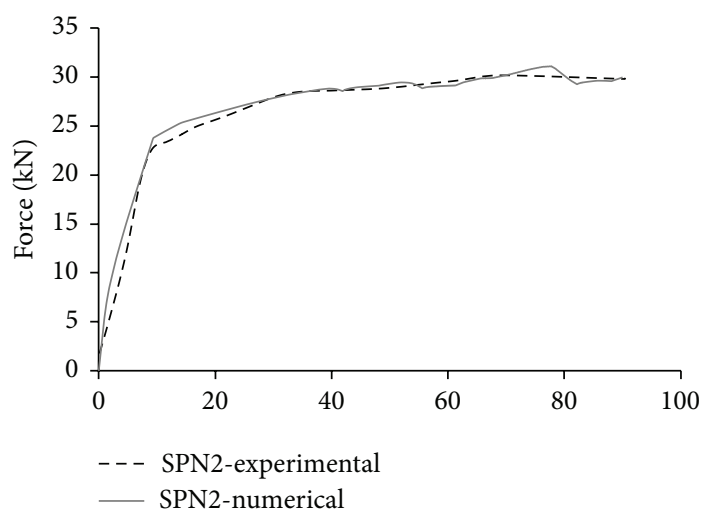

(s)

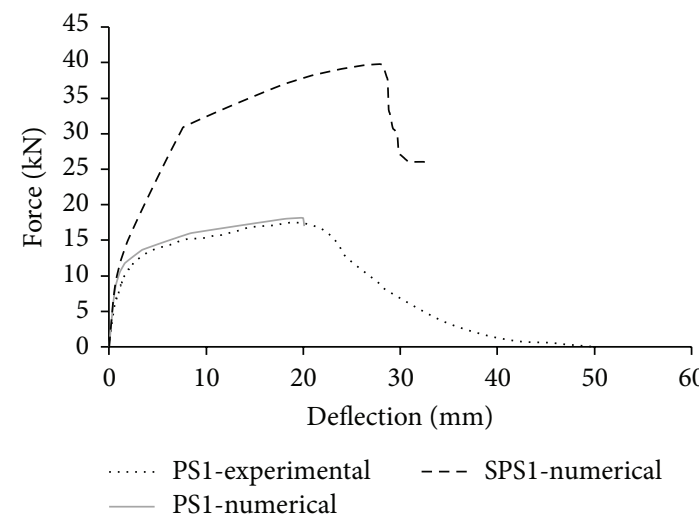

(u)

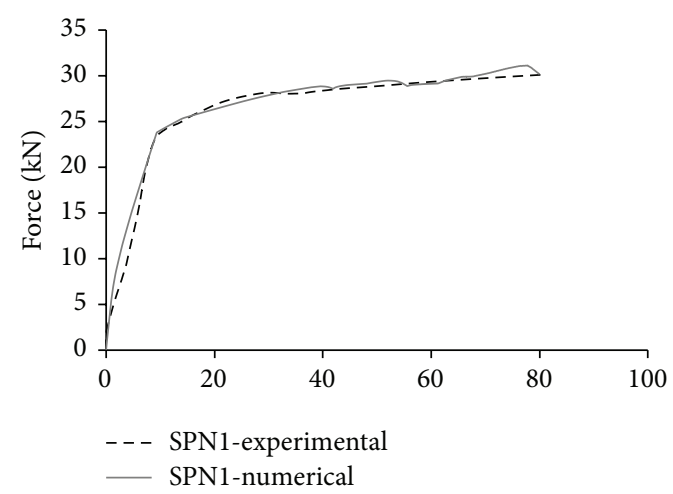

(r)

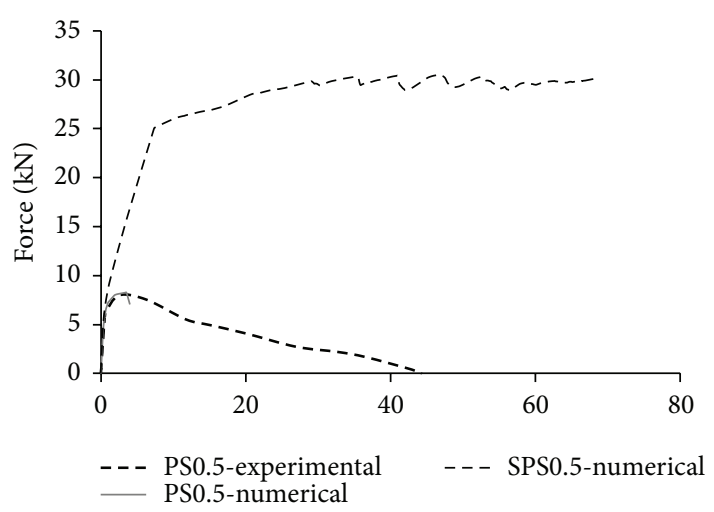

$(\mathrm{t})$

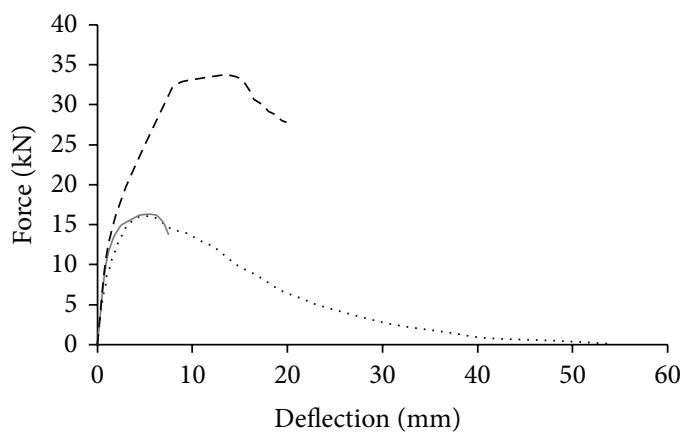

PS2-experimental _ - - SPS2-numerical PS2-numerical

(v)

FIGURE 16: Obtained numerical simulated results: (a) SNN; (b) SNS0.5; (c) SSS0.5; (d) SSS1; (e) SSS2; (f) SPP0.5; (g) SPP1; (h) SPP2; (i) SNS1; (j) SNS2; (k) SNP0.5; (l) SNP1; (m) SNP2; (n) SSN0.5; (o) SSN1; (p) SSN2; (q) SPN0.5; (r) SPN1; (s) SPN2; (t) SPS0.5 and SP0.5; (u) SPS1 and SP1; (v) SPS2 and SP2.

\section{Results and Discussions for Reinforced Functionally Graded RC Slabs with Steel Bars}

In this part, the most considerable reinforced concrete layer positions, fiber type, and fiber content were prepared and experimentally tested in [6]. The results demonstrated that the fiber type, fiber content, and reinforced concrete position have significant effects on the flexural performances of slabs [6]. To achieve the best flexural performance for composite multilayers slabs, the performance of fibers to increase load carrying capacity, ductility, absorbed energy, and number of formed cracks were considered as the main criteria [6]. According to the obtained numerical simulations in Figure 16, the simulated slabs had good agreement with the experimental results. In this direction, another case was selected to be analyzed which was not considered to be experimentally assessed as well as based on obtained experimental results the proposed numerically modeled slab could be able to have the best flexural performance. In the 

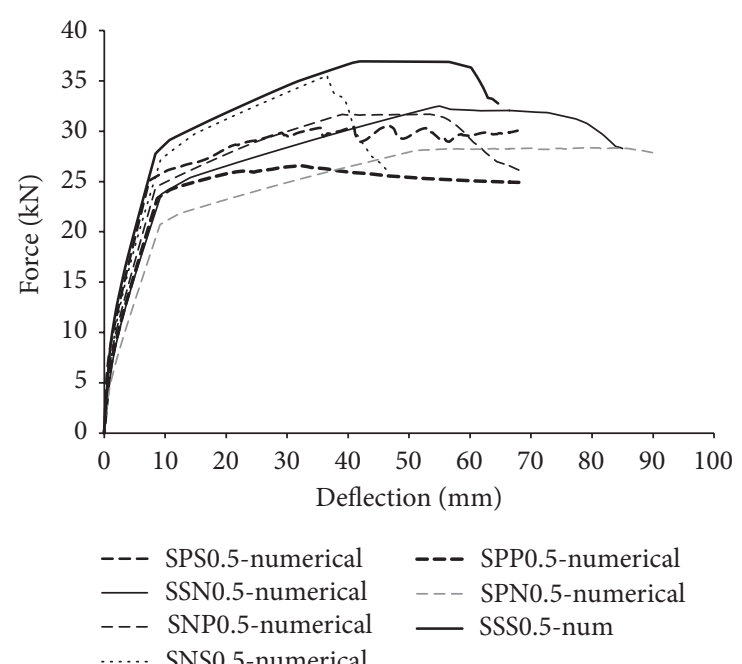

(a)
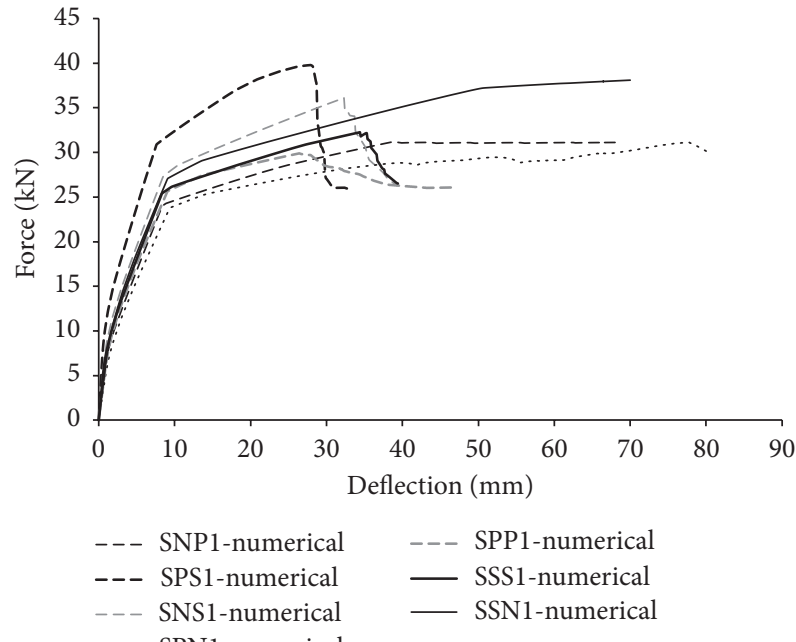

(b)

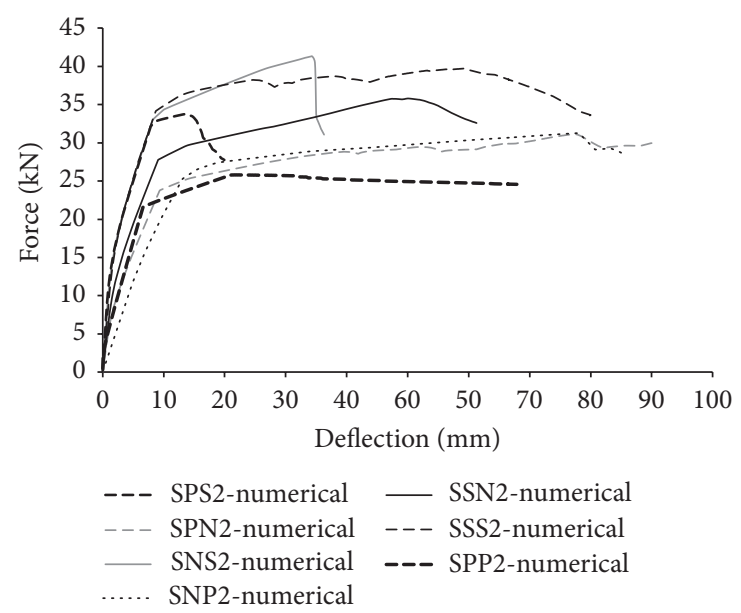

(c)

FIGURE 17: All considered cases for reinforced functionally graded RC slabs with steel bars.

TABLE 8: Mechanical properties of used steel bars.

\begin{tabular}{lcc}
\hline Name & Yielding stress (Mpa) & Ultimate stress (Mpa) \\
\hline Ф8 & 353 & 509 \\
Ф6 & 155 & 269 \\
\hline
\end{tabular}

proposed numerically modeled slab, top layer is reinforced by PP fibers and steel fibers are used to reinforce of bottom layer. Hence, the proposed numerical models with different fiber contents to reinforcement were simulated and assessed. All the simulated numerical models were illustrated and compared in Figure 17.

According to the obtained results, the best flexural performance for reinforced RC slabs with steel bars and $0.5 \%$ fiber volume fraction as fiber content was related to the slab which was entirely reinforced by steel fibers. Since then, the best flexural performance for functionally graded slabs was related to specimen SNS0.5. Load carrying capacity was decreased $18.63 \%$ in the specimen SPN0.5 in comparison to SSS0.5 while reinforcement of bottom layer wit $0.5 \%$ steel fiber led to $3.14 \%$ decrease in comparison to entirely reinforcement of cross section with $0.5 \%$ steel fiber volume fraction. Reinforcement of top layer by usage of $0.5 \%$ PP fiber in the proposed numerically model (SPN0.5) not only led to improve the flexural performance, but also decreased load carrying capacity and delicate the flexural performance. Since then, the specimen SPN1 obtained the maximum load carrying capacity among other reinforced functionally graded RC slabs with steel bars and 1\% fiber volume fraction. On the other hand, reinforcement of both top and bottom layers with $1 \%$ fiber volume fraction of PP and steel, respectively, led to significantly improve of flexural performance. According to the obtained results, using $1 \%$ fiber volume fraction to reinforcement of cross sections as functionally graded materials (SPS1) led to $23.48 \%$ increase in the load carrying capacity of slabs in comparison to entirely reinforcement with steel fiber (SSS1). This fact reveals that 

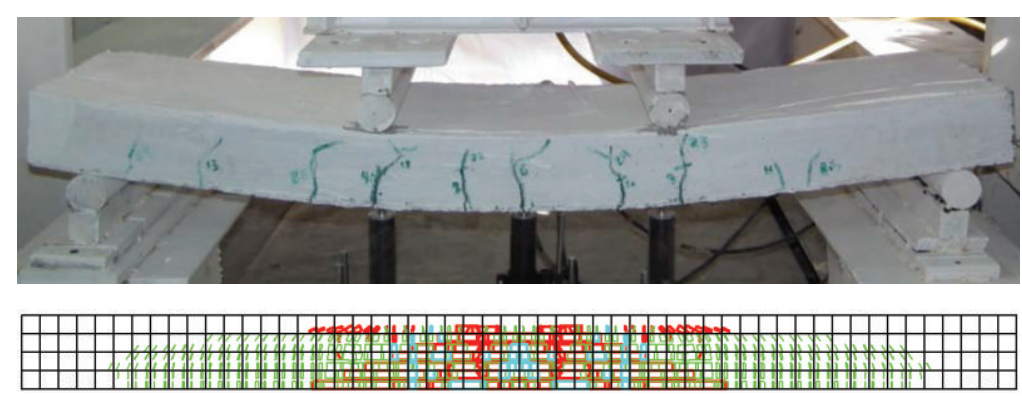

(a)
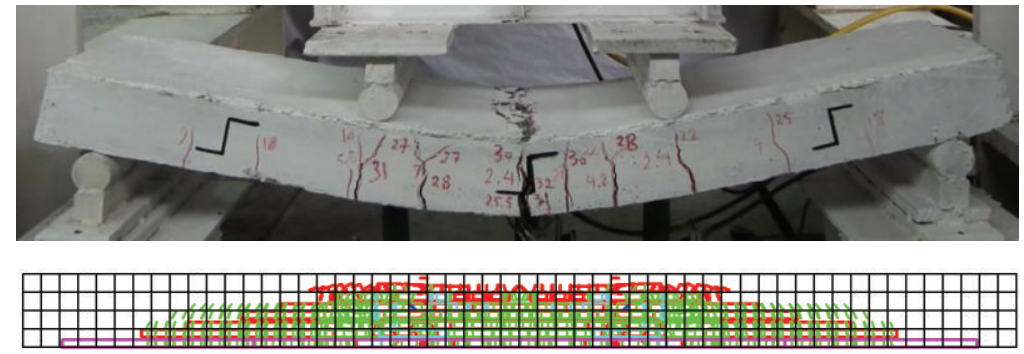

(b)
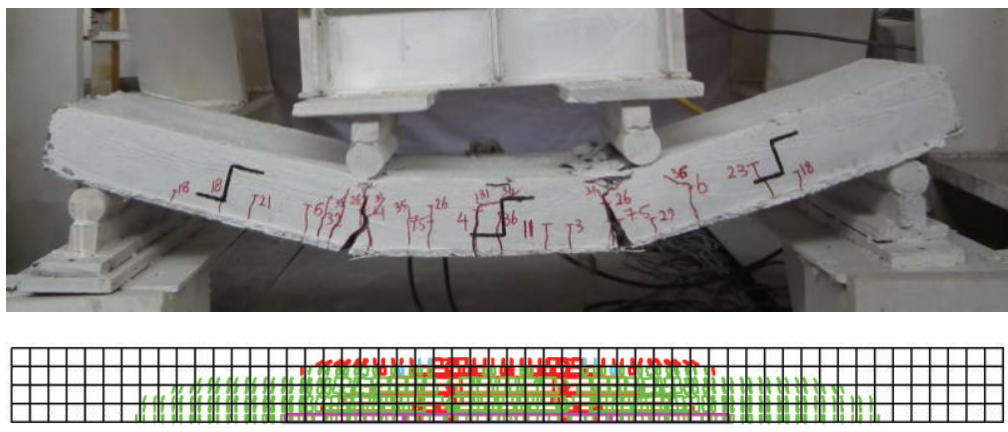

(c)
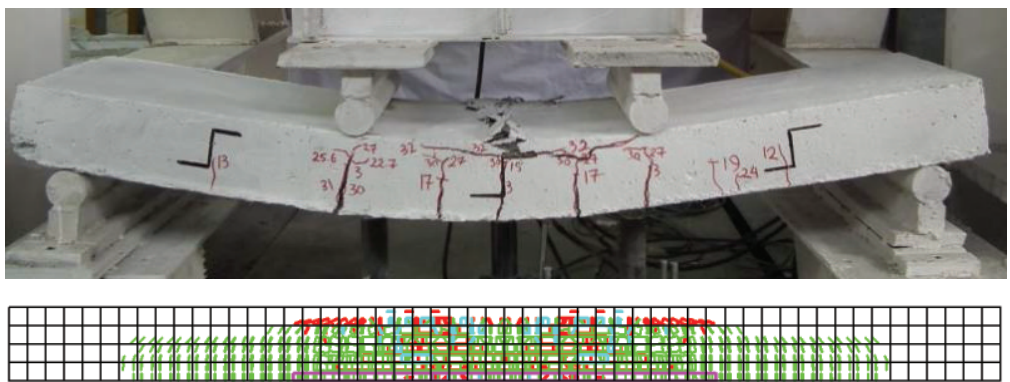

(d)
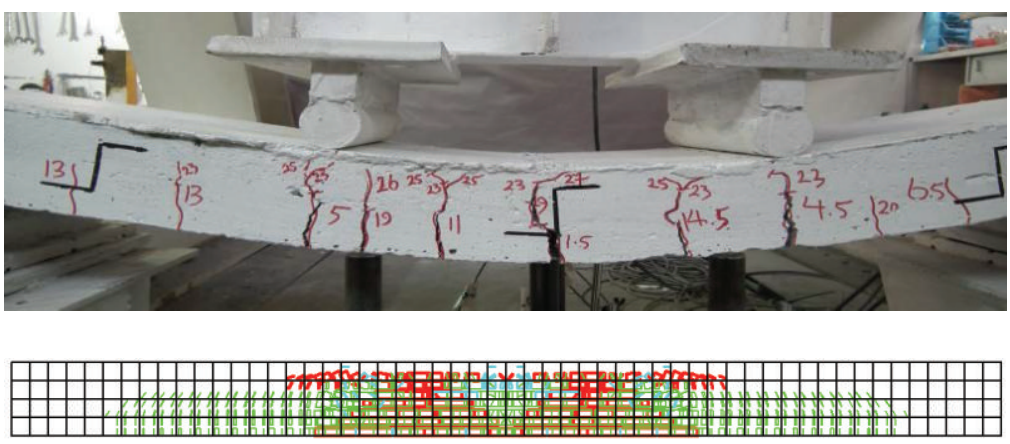

(e)

Figure 18: Continued. 

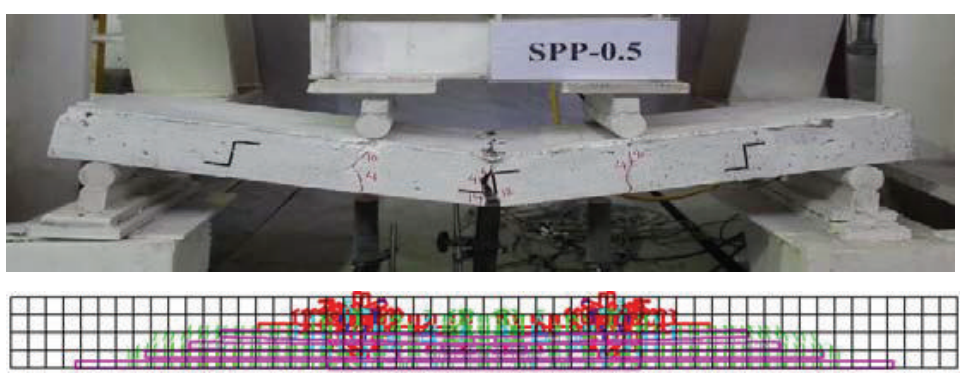

(f)
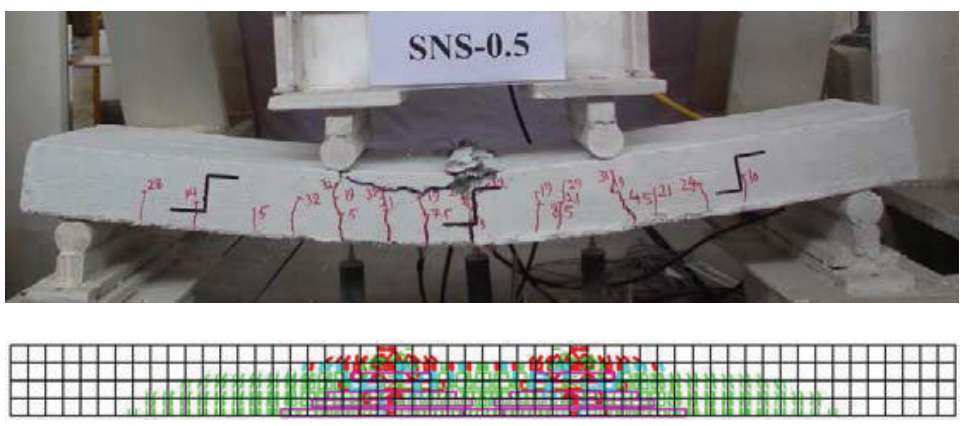

(g)
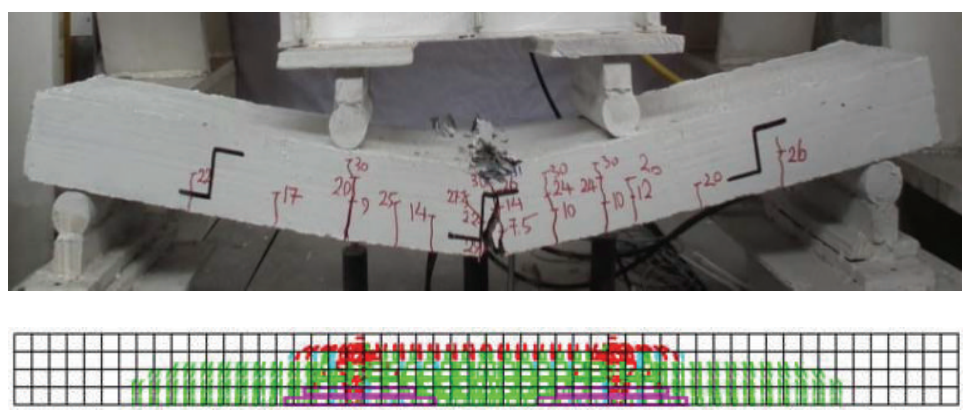

(h)

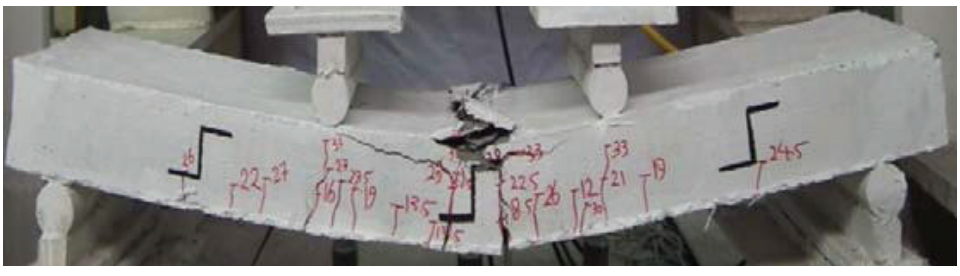

ЩПНАНА

(i)

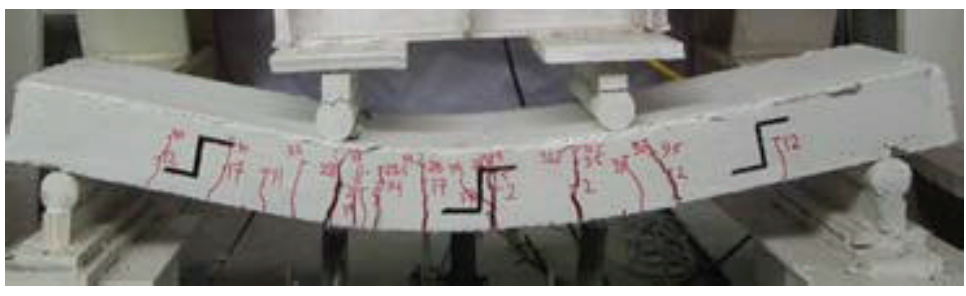

НПНН

(j)

FIGURE 18: Continued. 

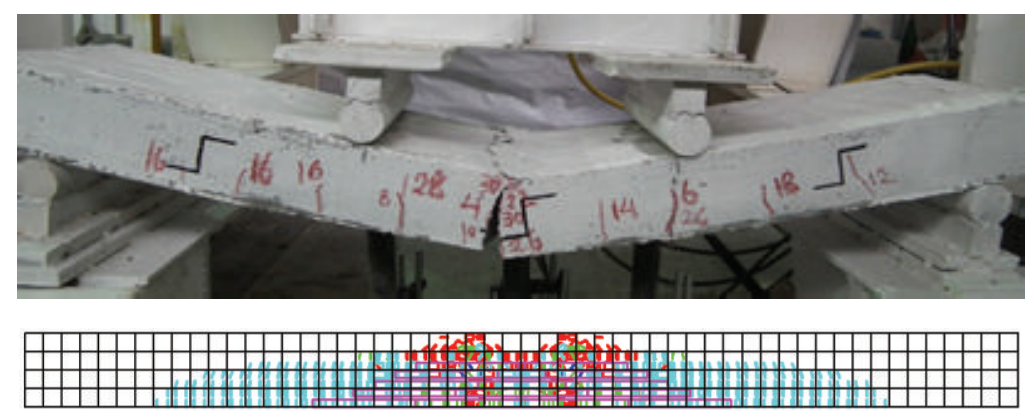

(k)
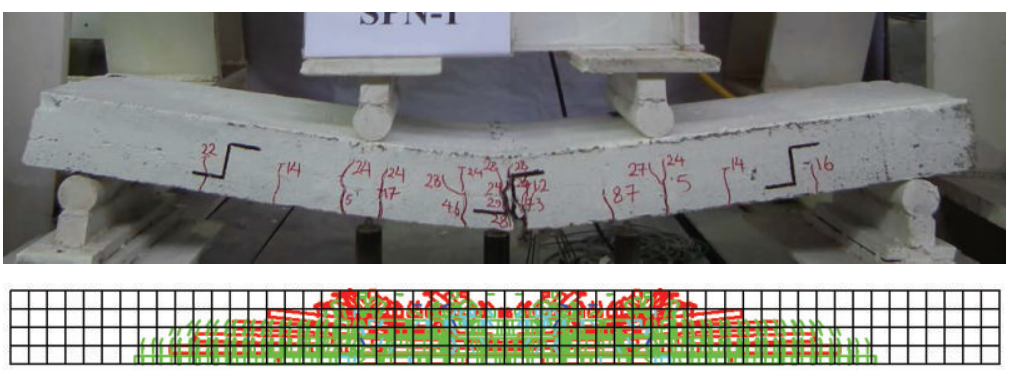

(1)
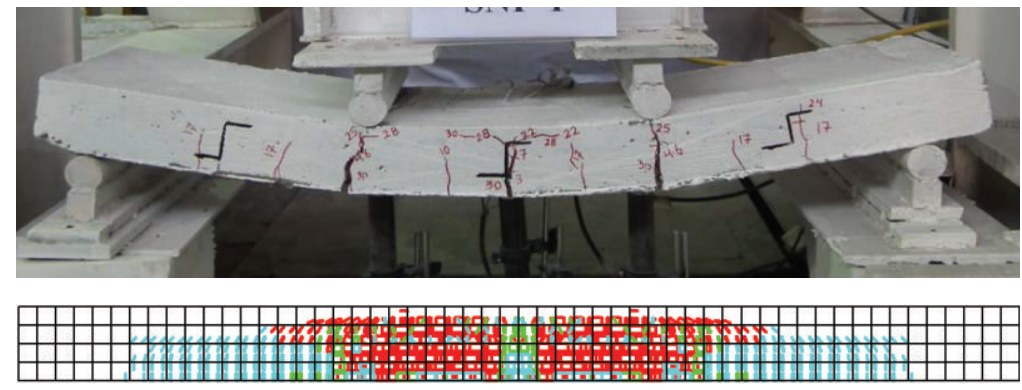

(m)

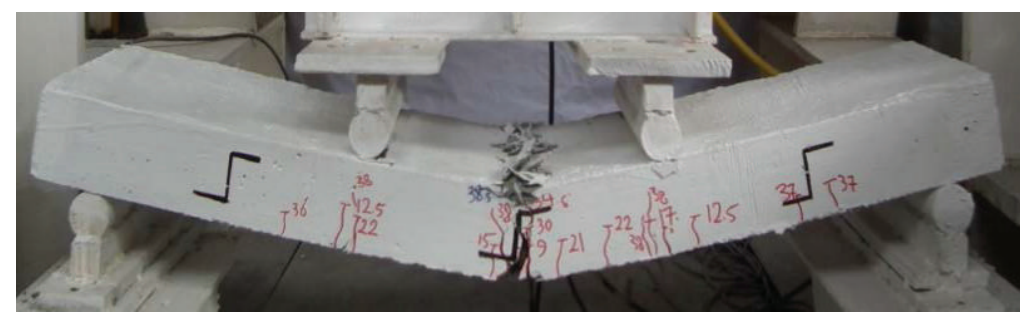

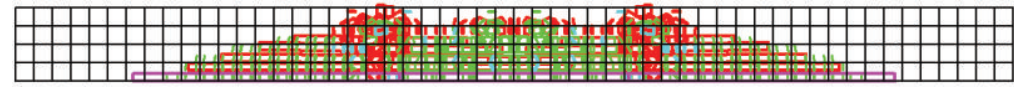

(n)
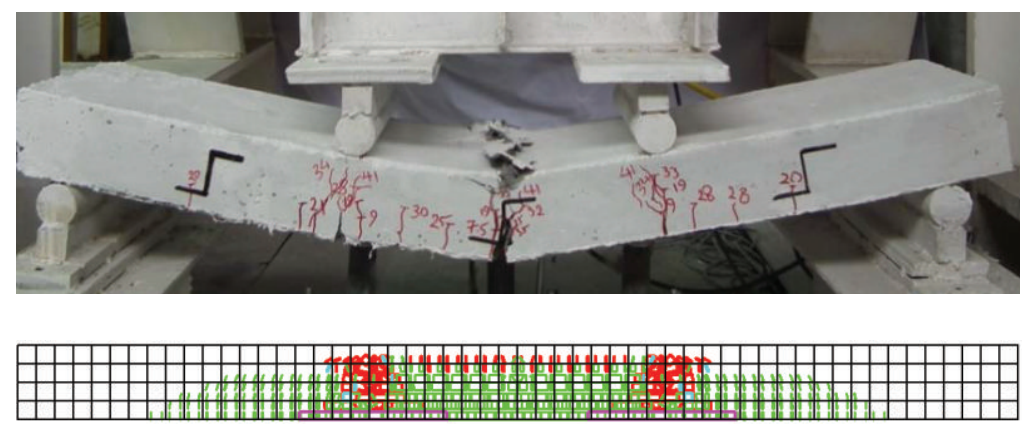

(o)

Figure 18: Continued. 

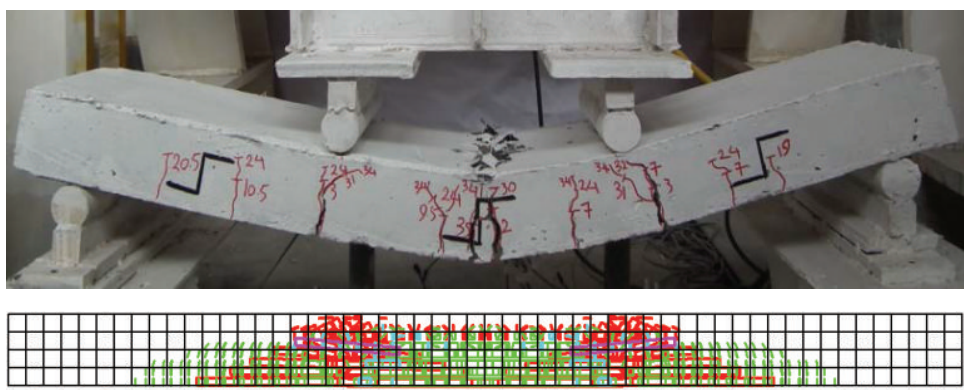

(p)
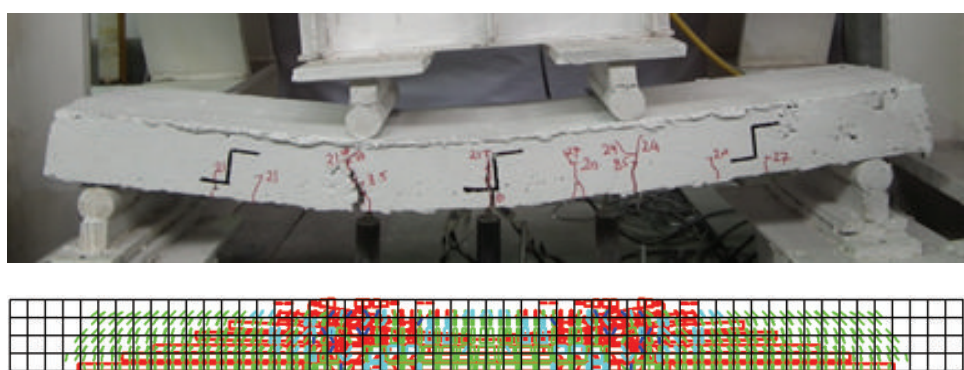

(q)
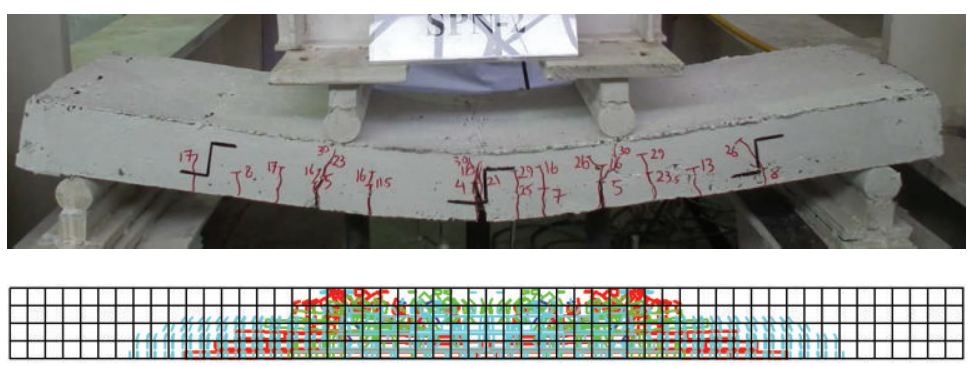

$(\mathrm{r})$
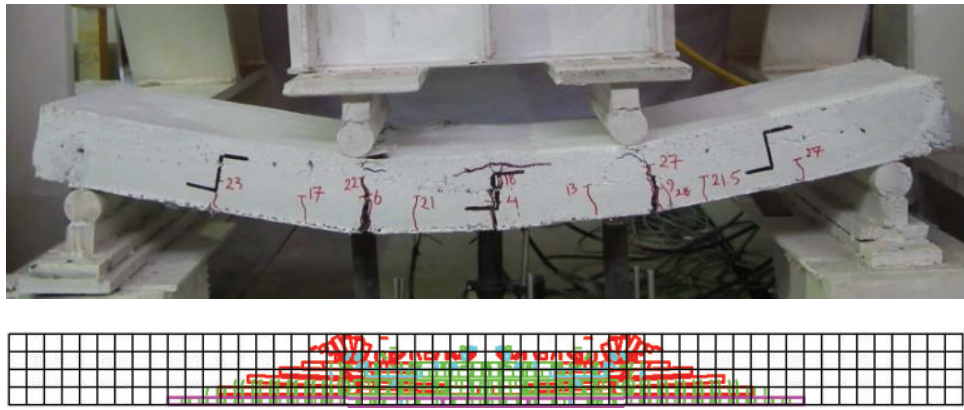

(s)

FIGURE 18: Experimental and numerical failures: (a) SNN; (b) SSN0.5; (c) SSS0.5; (d)SNP0.5; (e) SPN0.5; (f) SPP0.5; (g) SNS0.5; (h) SSS1; (i) SNS1; (J) SSN1; (k) SPP1; (l) SPN1; (m) SNP1; (n) SSS2; (o) SNS2; (p)SSN2; (q) SPP2; (r) SPN2; (s) SNP2.

the flexural performance and efficiency of proposed method in the reinforcement of cross sections as functionally graded materials in increasing load carrying capacity are significantly governed by fiber content, fiber type, and the positions of reinforced layer. Since, the best flexural performance in the slabs with $2 \%$ fiber volume fraction was achieved in the specimen SSS2. In the proposed numerical model (SPS2) the load carrying capacity was decreased $15.5 \%$ in comparison to the specimen SSS2 as well as the hardening flexural deflection in the specimen SSS2 was about four times more than specimen SPS2.

The failure modes for both experimental tests and numerical simulations are indicated in the Figure 18. The results showed that performing simulation of slabs by using plain stress elements has enough ability to achieve and predict accurate responses of slabs and formed crack patterns. 


\section{Conclusion}

Wide studies are conducted to develop new rehabilitation techniques by using reinforced concrete. Using reinforced functional graded concrete is one of the new techniques that some studies on this issue are applying. The present study was focused on the numerical evaluations of slabs that were reinforced as functional graded materials. In this direction, two series of numerical models were simulated which included (1) three specimens of unreinforced functionally graded RC slabs with steel bars; (2) nineteen specimens of reinforced functionally graded RC slabs with steel bars. Furthermore, some other cases, which were not experimentally tested, were modeled and considered to be evaluated the flexural performance. The numerical simulation results of unreinforced functionally graded RC slabs with steel bars are included.

The main criteria to approach the best flexural performance of the proposed slabs were (1) load carrying capacity; (2) ductility; (3) fracture energy; (4) economic aspects. Naghibdehi et al. used these four criteria to select the best flexural performance of slabs $[5,6]$. Regarding this point, the present study used these four criteria to achieve the best flexural performance. The best flexural and shear performance among reinforced functionally graded slabs were obtained in slab PS1 while SS2 was achieved for the reinforced entire cross-section concrete. In other words, reinforcement of slab as functionally graded with PP and steel fiber at top and bottom layers, respectively, with $1 \%$ fiber content led to observe hardening behavior in deflection. Furthermore, increasing steel fiber to reinforce the entire cross section led to achieve better shear and flexural performance while the best performance reinforced functionally graded slabs was achieved in slab PS1. By considering economic and engineering aspects, using PS1 would be able to be used instead of reinforced entire cross section with $1 \%$ or $2 \%$ steel fiber.

Furthermore, the numerical simulation results of reinforced functionally graded RC slabs with steel bars are included.

The best flexural performance of reinforced functionally graded RC slabs with steel bars with 0.5\% fiber volume fraction is related to SSS0.5. Entire reinforcement of slabs with $0.5 \%$ steel fiber volume fraction led to achieve the maximum load carrying capacity and hardening flexural deflections. Since, reinforcement of concrete layers with $1 \%$ fiber volume fraction as functionally graded materials led to achieve better flexural performances in comparison to entire reinforcement of cross sections. Furthermore, using $2 \%$ fiber volume fraction to reinforcement of concrete layers in the proposed specimens led to obtain the best flexural performance in the specimen SSS2.

Reinforcement of entire cross section with single fiber type led to have similar performance in slabs for using different fiber volume fractions while performance of reinforced slabs as functionally graded materials are significantly governed by fiber type and used fiber volume fractions of reinforcement and also the position of reinforced layer. According to the obtained results using this method in the slabs is looking very good and promising.

\section{Conflict of Interests}

The authors declare that there is no conflict of interests regarding the publication of this paper.

\section{References}

[1] R. F. Zollo, "Fiber-reinforced concrete: an overview after 30 years of development," Cement and Concrete Composites, vol. 19, no. 2, pp. 107-122, 1997.

[2] H. W. Reinhardt and A. E. Naaman, High Performance Fibre Reinforced Cement Composites, RILEM Publications, Paris, France, 1999.

[3] H. R. Pakravan, M. Jamshidi, and M. Latifi, "Investigation on polymeric fibers as reinforcement in cementitious composites: flexural performance," Journal of Industrial Textiles, vol. 42, no. 1, pp. 3-18, 2012.

[4] A. M. Brandt, "Fibre reinforced cement-based (FRC) composites after over 40 years of development in building and civil engineering," Composite Structures, vol. 86, no. 1-3, pp. 3-9, 2008.

[5] M. G. Naghibdehi, M. Mastali, M. K. Sharbatdar, and M. G. Naghibdehi, "Flexural performance of functionally graded RC cross-section with steel and PP fibres," Magazine of Concrete Research, vol. 66, no. 5, pp. 219-233, 2014.

[6] M. G. Naghibdehi, M. K. Sharbatdar, and M. Mastali, "Repairing reinforced concrete slabs using composite layers," Journal of Materials and Design, vol. 58, pp. 136-144, 2014.

[7] J. G. Rots, Computational modeling of concrete fracture [Ph.D. thesis], Delft University of Technology, Delft, Netherlands, 1988.

[8] J. M. Sena-Cruz, Strengthening of concrete structures with nearsurface mounted CFRP laminate strips [Ph.D. thesis], Department of Civil Engineering, University of Minho, Braga, Portugal, 2004.

[9] J. A. O. Barros, I. G. Costa, and A. Ventura-Gouveia, "CFRP flexural and shear strengthening technique for RC beams: experimental and numerical research," Advances in Structural Engineering, vol. 14, no. 3, pp. 551-571, 2011.

[10] Committee 318 ACI, Building Code Requirements for Structural Concrete (ACI, 95), American Concrete Institute, 1988.

[11] BS EN 1992-1-1: 2004, Design of Concrete Structures, General Rules and Rules for Building, 2004.

[12] Concrete Code Iranian, Design and Analysis Rules of Concrete Structures, Management and Planning Organization of Iran, Tehran, Iran, 2005.

[13] J. M. Sena-Cruz, Strengthening of concrete structures with nearsurface mounted CFRP laminate strips [Ph.D. thesis], Department of Civil Engineering, University of Minho, 2004. 

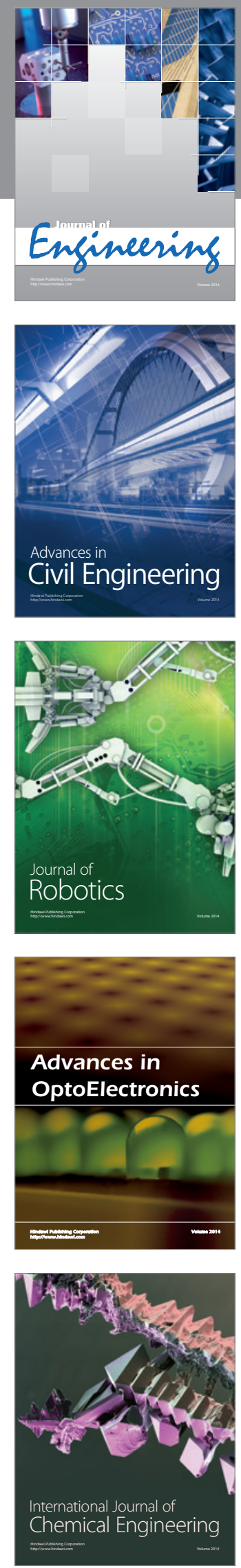

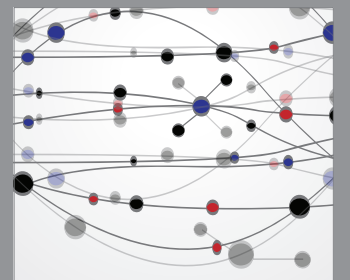

The Scientific World Journal
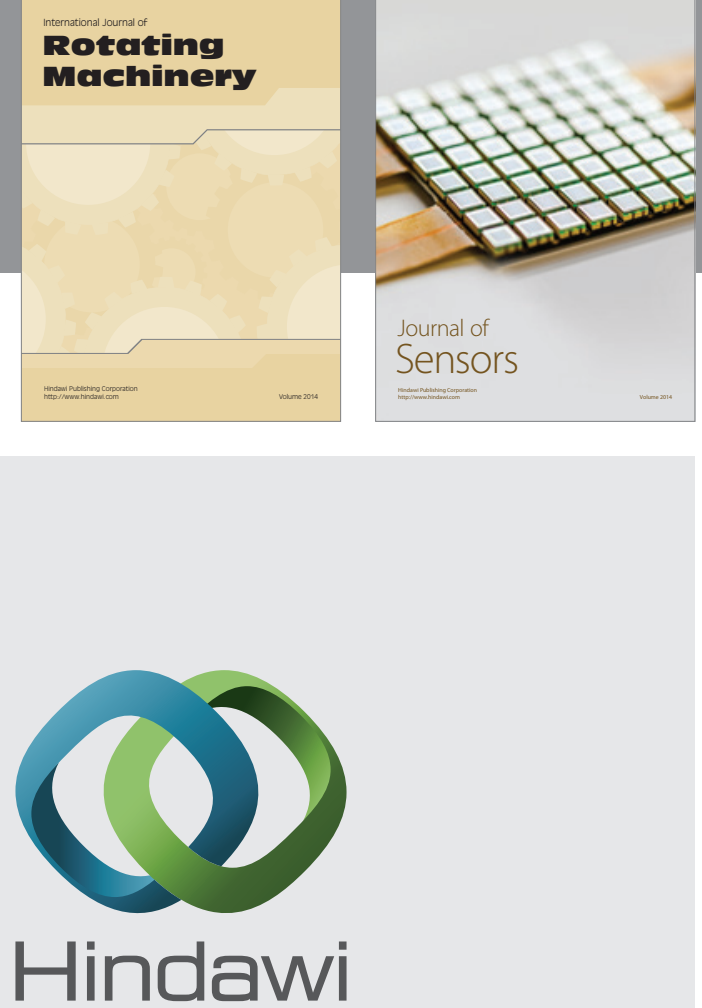

Submit your manuscripts at http://www.hindawi.com
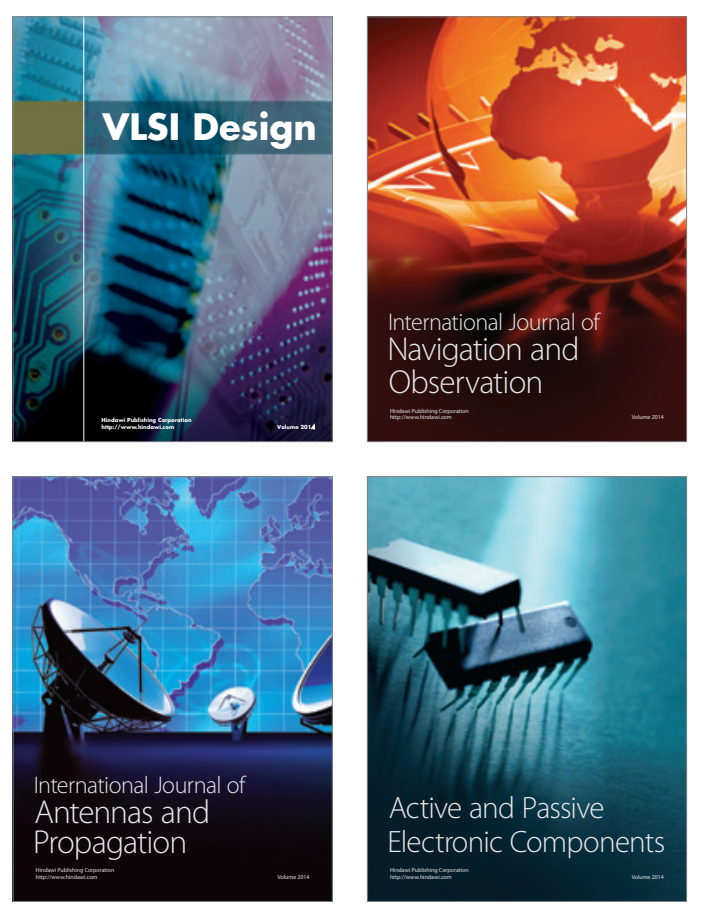
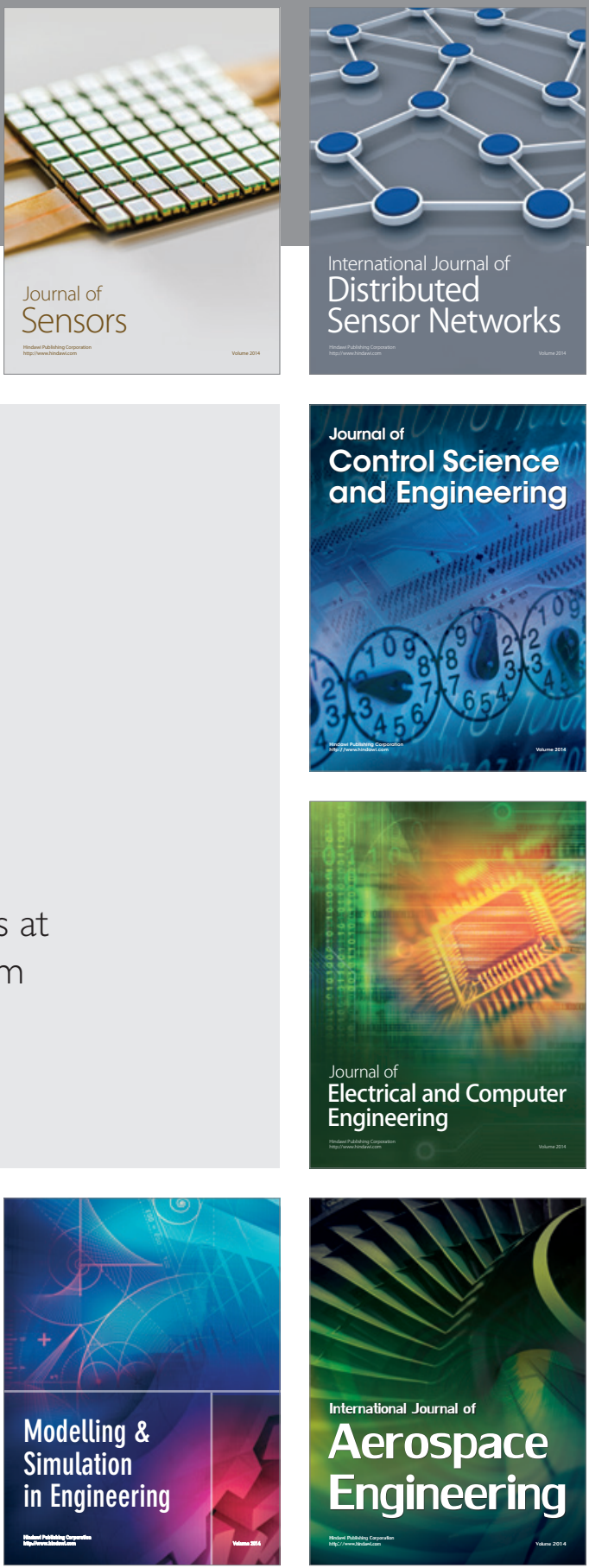

Journal of

Control Science

and Engineering
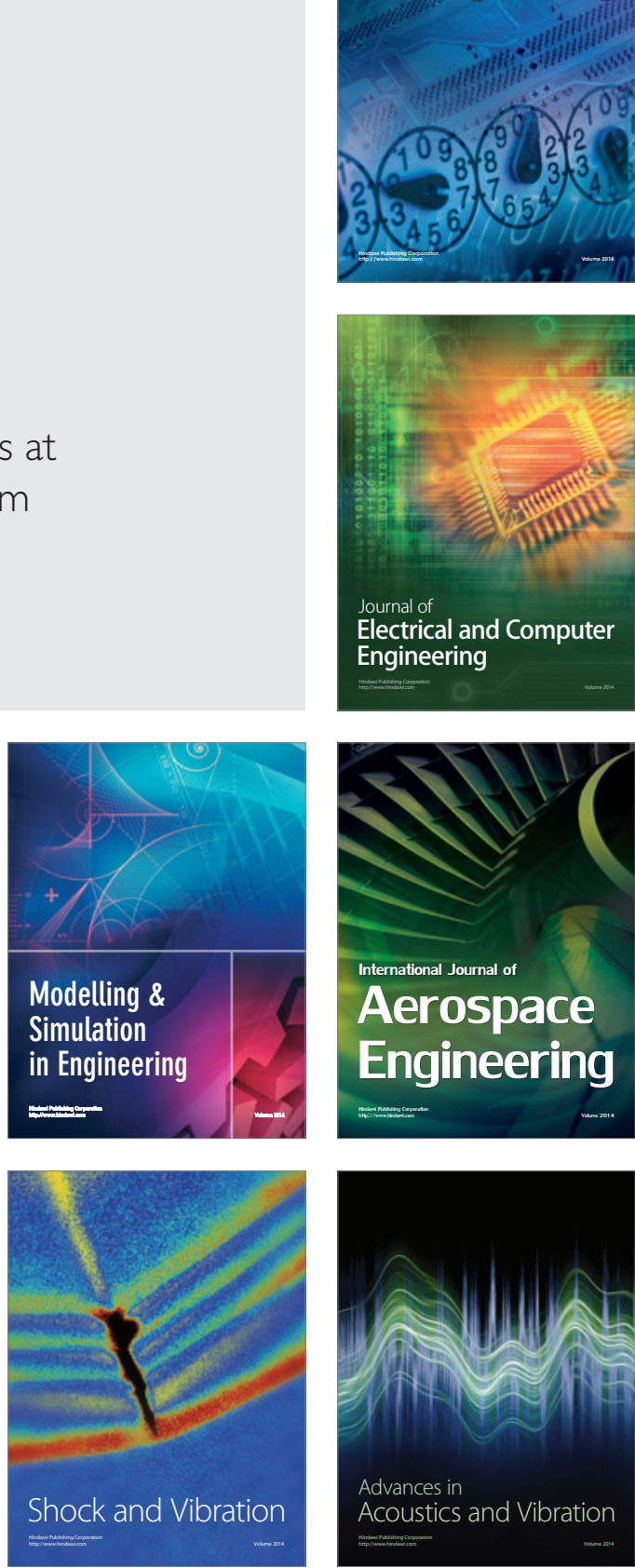